\title{
Cancer vaccines from cryogenically silicified tumour cells functionalized with pathogen- associated molecular patterns
}

\author{
Jimin Guo ${ }^{1,4}$, Henning De May ${ }^{2,4}$, Stefan Franco', Achraf Noureddine ${ }^{3}$, Lien Tang ${ }^{3}$, C. J. Brinker ${ }^{3}$, \\ Donna F. Kusewitt', Sarah F. Adams ${ }^{2}$ and Rita E. Serda ${ }^{1}{ }^{1 凶}$
}

\begin{abstract}
The production of personalized cancer vaccines made from autologous tumour cells could benefit from mechanisms that enhance immunogenicity. Here we show that cancer vaccines can be made via the cryogenic silicification of tumour cells, which preserves tumour antigens within nanoscopic layers of silica, followed by the decoration of the silicified surface with pathogen-associated molecular patterns. These pathogen-mimicking cells activate dendritic cells and enhance the internalization, processing and presentation of tumour antigens to T cells. In syngeneic mice with high-grade ovarian cancer, a cell-line-based silicified cancer vaccine supported the polarization of $\mathrm{CD4}^{+} \mathbf{T}$ cells towards the T-helper-1 phenotype in the tumour microenvironment, and induced tumour-antigen-specific T-cell immunity, resulting in complete tumour eradication and in long-term animal survival. In the setting of established disease and a suppressive tumour microenvironment, the vaccine synergized with cisplatin. Silicified and surface-modified cells from tumour samples are amenable to dehydration and room-temperature storage without loss of efficacy and may be conducive to making individualized cancer vaccines across tumour types.
\end{abstract}

$\mathrm{R}$ ecent advances in strategies to engage the immune system for cancer therapy have established immunotherapy as an option for cancer treatment ${ }^{1}$. Evidence that cancer can elicit tumour-specific immune responses has additionally spurred the development of therapeutic vaccines ${ }^{2-4}$; however, the clinical efficacy of tumour vaccines is hindered by a lack of broadly expressed tumour antigens in many cancers. To circumvent this, autologous tumour cells have been used for the construction of polyclonal individualized tumour vaccines, addressing the lack of universally expressed tumour antigens and the risk of immune escape with treatments that target single antigens. Neoantigens can be highly immunogenic; however, immunosuppressive mechanisms that evolve during cancer progression dampen effective anti-tumour immune responses ${ }^{5,6}$. Efforts to overcome suppressive effects of the tumour microenvironment in designing cell-based vaccines include ex vivo genetic modification of tumour cells, electroporation/ co-incubation of tumour cell lysate or personalized peptides with autologous dendritic cells (DC $)^{7-10}$, as well as the use of pathogens or pathogenic components as vaccine adjuvants ${ }^{11,12}$. Although these approaches show promise, clinical applications have been limited by lengthy and complex production requirements ${ }^{6}$. Here we show that advances in materials science, specifically cell cryo-silicification, can be leveraged to overcome these hurdles to rapidly create stable biomineralized tumour cells that function as a modular vaccine for the development of a highly effective personalized immune therapy.

Various organisms, such as hot-spring bacteria ${ }^{13}$ and unicellular diatoms ${ }^{14}$, create amorphous silica exoskeletons from environmentally available soluble silica within acidified compartments that protect them from environmental stressors and mediate permeability and osmotic stress. In previous work, we showed that the immersion of fixed cells in acidified solutions of soluble silica preserved cellular features via a self-limiting biosilicification process wherein soluble silica was catalytically condensed to form nanoscopic amorphous silica coatings proximal to interfacial cationic proteins at all intracellular and extracellular biomolecular interfaces ${ }^{15}$. Here we improved the biosilicification process and adapted it for vaccine development through a cryo-silicification process that avoids aldehyde fixation to create a modular vaccine that preserves an individual patient's cancer neoantigens. Further, the thin hydroxylated silicified $(\mathrm{Si})$ cell surface enables modification with biofunctional moieties (here Toll-like receptor (TLR) ligands) to enhance cell immunogenicity and direct downstream immune responses for therapeutic benefit ${ }^{16,17}$.

TLRs on the surface of DC recognize highly conserved pathogen-associated molecular patterns (PAMPs). For example, TLR4 recognizes lipopolysaccharide (LPS), or its derivative monophosphoryl lipid A (MPL), from Gram-negative bacteria, whereas TLR9 recognizes bacterial hypomethylated CpG DNA motifs. We previously reported enhanced phagocytosis of microparticles by DC through MPL binding to the microparticle surface. This was accompanied by increased DC expression of CD40, CD80, CD86, as well as major histocompatibility complex (MHC) class I and II molecules ${ }^{18}$. This study examines the impact of coating Si tumour cells with TLR ligands on DC functions, with an emphasis on internalization, antigen presentation and therapeutic efficacy of the resulting bacterial mimic cancer vaccine. An advantage of attaching TLR ligands to the Si cell surface is multivalent activation of surface and endosomal TLRs on antigen presenting cells (APC) $)^{16,19,20}$. In addition to enhancing endocytosis, TLR ligands affect phagosomal maturation governing proteolytic activity and peptide generation, and have downstream effects such as fusion with the MHC class II compartment, expression of co-stimulatory molecules and

'Department of Internal Medicine, University of New Mexico Health Science Center, Albuquerque, NM, USA. '2Department of Obstetrics \& Gynecology, University of New Mexico Health Science Center, Albuquerque, NM, USA. ${ }^{3}$ Department of Chemical and Biological Engineering, University of New Mexico, Albuquerque, NM, USA. ${ }^{4}$ These authors contributed equally: Jimin Guo, Henning De May. $\varpi_{e}$-mail: rserda@salud.unm.edu 
cytokine production driving T-cell polarization ${ }^{21,22}$. The combination of TLR4 and TLR9 agonists has been shown to polarize macrophages, DC and natural killer cells towards a T-helper-(Th)1 phenotype $^{16}$, thereby directing and amplifying anti-tumour immune responses.

Here we demonstrate the therapeutic impact of a vaccine composed of Si cancer cells presenting TLR ligands in syngeneic ovarian cancer models. Using high-grade serous syngeneic ovarian cancer mouse models, we show the induction of protective tumour antigen-specific T-cell immunity and complete elimination of established tumours in vaccinated mice. While these experiments show the efficacy of Si-cell vaccines in ovarian cancer, this modular approach to cancer vaccine development can be adapted broadly for other tumour types.

\section{Results}

Tumour cell silicification establishes a modular approach for vaccine development. Ex vivo silicification of cancer cells as a method of fixation enables preservation of cell integrity and the biofunctionality of proteinaceous components, and enables surface functionalization with PAMPs (Fig. 1a). Importantly, this process represents a significant advance over prior work on cellular silicification ${ }^{15}$ by eliminating aldehyde fixation, enabling improved biofunctionality of cellular components and removing the use of this cytotoxic material as a means of cell preservation. Cryo-silicification is technically simple and can be extended to any arbitrary cell type enabling personalization. In our standard procedure, cancer cells at a density of $3 \times 10^{6}$ cells per $\mathrm{ml}$ are suspended in a hypotonic aqueous solution of $100 \mathrm{mM} \mathrm{NaCl}$ and $10 \mathrm{mM}$ tetramethyl orthosilicate at $\mathrm{pH} 3.0$ for $10 \mathrm{~min}$ and then maintained for $24 \mathrm{~h}$ at $-80^{\circ} \mathrm{C}$. With the goals of preserving cell integrity, limiting silica layer thickness and avoiding cell aggregation, $\mathrm{NaCl}$ and TMOS concentrations were optimized (Supplementary Figs. 1 and 2). Scanning electron microscopy (SEM) and energy dispersive spectroscopy (EDS) analysis of $\mathrm{Si}$ murine ovarian cancer cells confirmed the presence of organic matter ( $\mathrm{C}$ and $\mathrm{O})$ and elemental silicon (Fig. 1b). Inductively coupled plasma-optical emission spectroscopy (ICP-OES) analysis of Si cells shows that this approach resulted in significantly lower silica content compared with silicification under higher silicic acid concentrations or temperature (Fig. 1c, left). Specifically, the overall extent of silica deposition/thickness was reduced 55-fold compared with published processes used for cell silicification ${ }^{15}$. This is important as it allows rapid silica dissolution (Fig. 1c, right), enabling the biomolecular functionality of the cellular components.

For these experiments, we employed high-grade syngeneic ovarian cancer models. The BR5-Akt cell line, kindly provided by Dr Sandra Orsulic, was used for the majority of experiments because this model was developed on an FVB background, facilitating in vivo imaging with the IVIS spectrum. An ID8ova cell line, developed from the ID8 cancer model established in a C57BL/6 strain and transduced to express the model antigen ovalbumin was used for in vitro assessments of tumour antigen specificity.

Surface modification of Si cells to enable functionalization. The innovation of this approach to tumour cell fixation for vaccine development is based on the properties of silica that enable surface binding of adjuvants or other immunomodulatory compounds. The native chemistry of the Si cell surface is dominated by hydroxyl (silanol $\mathrm{Si}-\mathrm{OH}$ ) groups. At physiological $\mathrm{pH}$, the silanol groups are largely dehydroxylated, creating an anionic $\left(\mathrm{Si}_{-}-\mathrm{O}^{-}\right)$surface that adsorbs cationic molecules and polymers that in turn can adsorb and retain anionic ligands. Adsorption of polyethyleneimine (PEI), polylysine, or chitosan on the Si cell surface each reversed the negative Si-cell surface/zeta potential (Fig. 2d and Supplementary Fig. 3a). Further, based on zeta-potential analysis, PEI, unlike the other cationic molecules, facilitated homogeneous MPL binding to the $\mathrm{Si}$ cell surface (Supplementary Fig. 3b), and optimal activation of DC based on CD40 surface expression (Supplementary Fig. 3c). PEI, an organic cationic polymer that has been reported to be a TLR4 or TLR5 ligand with the ability to increase the immunogenicity of DNA-based vaccines and nanoparticles ${ }^{23-25}$, displayed higher binding to Si cells compared with aldehyde-fixed cells using zeta potential as a metric for cell modification (Supplementary Fig. 3d). On the basis of these cumulative properties, PEI was selected for vaccine development. We next selected two TLR agonists for Si-cell surface modification and optimized binding capacity (Supplementary Fig. 4). Due to the reported syngergistic activity and $T_{H} 1$ skewing by CpG and MPL in cancer models ${ }^{25,26}$, we compared single and dual agonist effects using our BR5-Akt mouse model. Vaccination with Si-PEI-CpG-MPL BR5-Akt (hereafter Si vaccine) cells resulted in optimal treatment outcomes (Extended Data Fig. 1). A vaccine dose of $3 \times 10^{6}$ cells (optimized herein) contains approximately $5 \mu \mathrm{g}$ $\mathrm{CpG}, 4 \mu \mathrm{g}$ MPL, $54 \mu \mathrm{g}$ PEI and $0.2 \mu \mathrm{g}$ silica, with a mass ratio of 1,000:0.06:18:1.7:1.4 for cells:Si:PEI:CpG:MPL (assuming a mass of $1 \mathrm{mg}$ for $1 \times 10^{6}$ cells; Fig. $\left.1 \mathrm{e}\right)$.

Si cells are safe for use in vivo. To evaluate the safety of Si vaccine cells for cancer treatment, we assessed their viability in vitro and in vivo. During vaccine preparation, cancer cells were exposed to an acidic, hypotonic silicic acid solution, followed by freezing at $-80^{\circ} \mathrm{C}$, and surface modification. Using an absence of ATP production as an in vitro measure of metabolic activity, these processing methods resulted in complete cell death (Fig. 1f). Si cells were then incubated in $0.2 \mathrm{mg} \mathrm{ml}^{-1}$ PEI for $10 \mathrm{~min}$. PEI is a cationic macromolecule, and both branched and linear free PEI can compromise membrane integrity and initiate cell apoptosis ${ }^{27}$. We have reported that while small nanoparticles can be cytotoxic in vitro under typical cell culture conditions, larger entities coated with PEI do not induce toxicity ${ }^{28}$. In addition, in the presence of physiologically relevant levels of serum, the cationic surface charge of PEI-coated particles is masked with serum proteins, mitigating the biological impact. As an additional assessment for viability, cellular uptake of propidium iodide (PI) was evaluated by flow cytometry. Notably, scatter dotplots of live or Si tumour cells supported retention of cell structure following silicification, as expected. In these experiments, all Si cells displayed intracellular PI staining (Fig. 1g), confirming that Si cells are not viable. Finally, to ensure that these cells could not establish tumours in vivo, luciferase-positive Si cells were injected intraperitoneally into mice and tumour growth was assessed for $25 \mathrm{~d}$. None of these mice developed any bioluminescent evidence of tumour viability (Fig. 1h). Additionally, mice injected with Si vaccine cells by subcutaneous administration lacked evidence of any tumour at the injection site by histologic assessment (Supplementary Fig. 5). With confirmation that Si tumour cells can be safely administered in vivo, we proceeded with further vaccine optimization.

Surface modification of Si cells with TLR agonists enhances DC uptake and activation. Engagement of TLR4 and TLR9 on APC has been shown to promote antigen internalization, cytokine secretion and expression of co-stimulatory molecules and $\mathrm{MHC}^{16}$. To test whether surface modification with CpG and MPL promoted Si vaccine cell uptake and processing by APC, we performed co-culture experiments with bone marrow-derived DC (BMDC) ex vivo. Confocal microscopy and flow cytometry confirmed that $\mathrm{Si}$ vaccine cells were engulfed by DC in vitro within $1 \mathrm{~h}$ (Fig. 2a-c and Extended Data Fig. 1a). To specifically track Si vaccine cells (blue, actin; green, tubulin; violet, DAPI), they were loaded with fluorescent nanoparticles (red, rhodamine B) before silicification (Fig. 2a). The actin fluorescence is shown with variable thresholding in Fig. 2a (blue) and $2 \mathrm{~b}$ (red) to enable identification of intracellular and surface-bound modified Si tumour cells. Internalization of Si-PEI-CpG-MPL, Si-PEI or Si-only tumour cells by DC was compared with that of live 
a
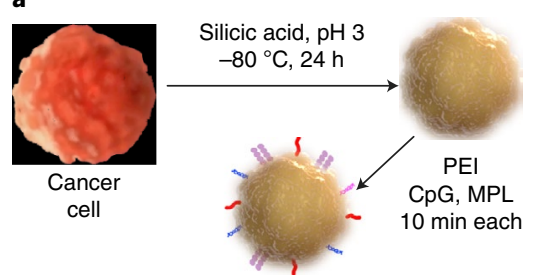

C

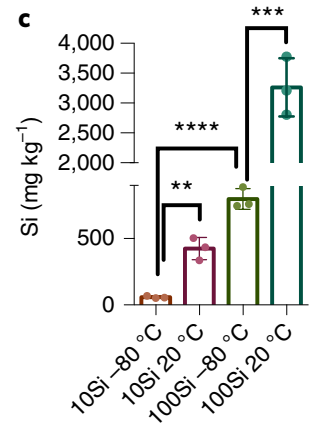

f

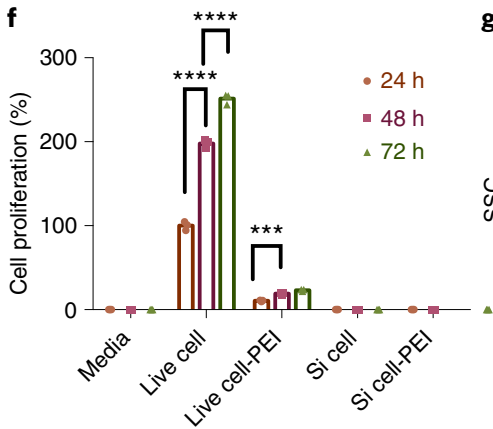

b
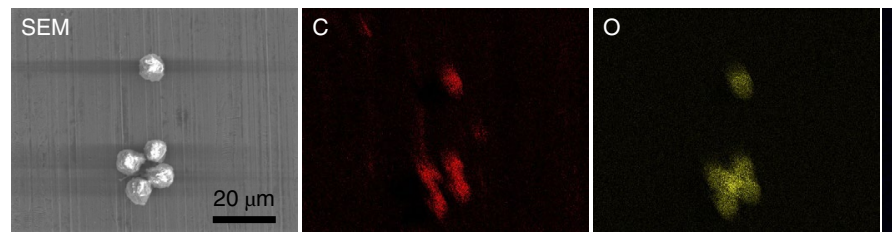

Si

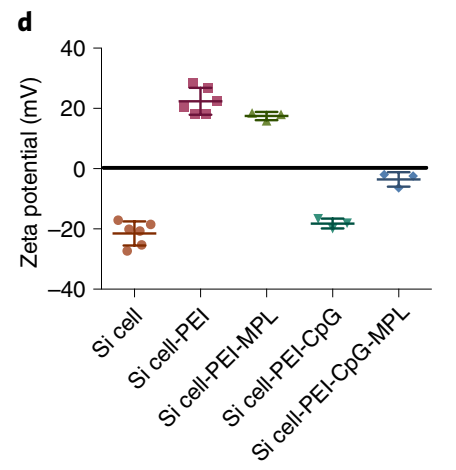

e

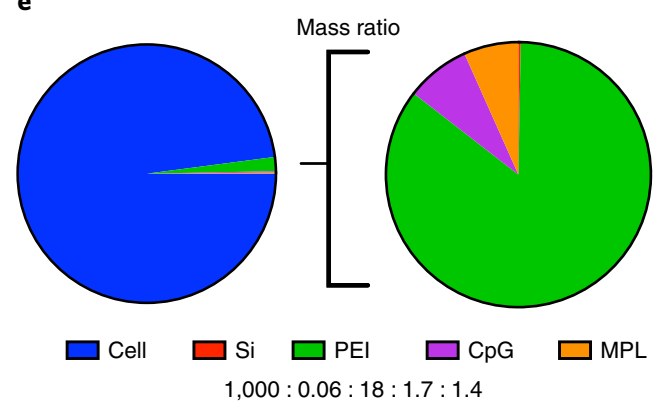

h

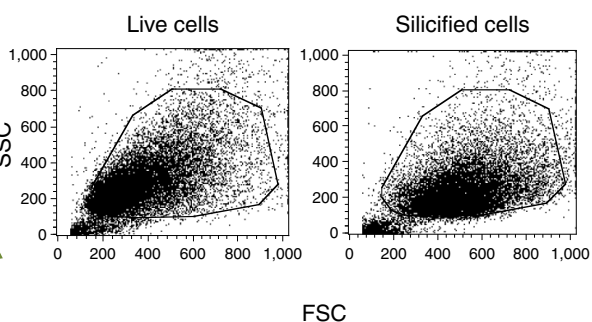

FSC

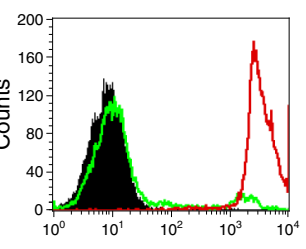

$\mathrm{Pl}$

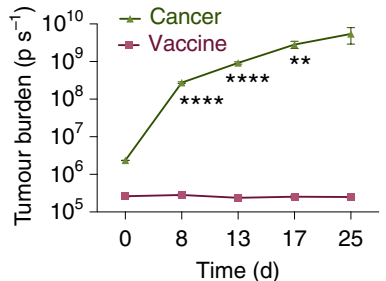

Fig. 1 | Characterization of Si cancer cells. a, Cryo-silicification and adsorption of PAMPs to cancer cells. Blue motifs, CpG; purple motifs, MPL; red motifs, PEI. b, Confirmation of Si content in Si BR5-Akt tumour cells using SEM and energy dispersive X-ray analysis of carbon (C), oxygen (O) and silicon (Si). c, ICP-OES analysis of Si content in BR5-Akt cells silicified using either 10 or $100 \mathrm{mM}$ silicic acid solution for $24 \mathrm{~h}$ at $20^{\circ} \mathrm{C}$ or $-80^{\circ} \mathrm{C}$ (left) $\left(20^{\circ} \mathrm{C}\right.$ versus $80^{\circ} \mathrm{C}$ at $10 \mathrm{Si}(P=0.0017)$ and $100 \mathrm{Si}(P=0.001)$; centre values 59, 424, 798 and 3263; s.d. error bars; $n=3$ biological replicates; unpaired two-tailed parametric $t$-tests); and Si content in $10 \mathrm{mM}$ cryo-silicified cells before and after $72 \mathrm{~h}$ in simulated endosomal fluid (right) $(P=0.0002$; centre values 57 and 10; s.d. error bars; $n=3$ to 4 biological replicates; unpaired two-tailed parametric $t$-test). d, Zeta-potential analysis of Si cells with different surface modifications ( $n=3$ to 6 biological replicates per group; centre values $-22,22,17,-18$ and -4 ; s.d. error bars). e, Pie charts showing Si-PEI-CpG-MPL cell composition by mass ratio. f, Cell-Glo proliferation assay of live or Si BR5-Akt cells with and without a 10 min immersion in $0.2 \mathrm{mg} \mathrm{ml}{ }^{-1} \mathrm{PEI}$ measured at 24,48 and $72 \mathrm{~h}$ ( $n=5$ biological replicates; $P=0.0002$, unpaired two-tailed parametric $t$-test for 24 versus $48 \mathrm{~h}$ for live cells with PEl; for live cell and live cell PEI, centre values 22, 44 and 55; s.d. error bars). g, Flow cytometry scatter dotplots of live or Si BR5-Akt cells showing increased forward light scatter (FSC) with silicification and histogram of cells before and after staining with propidium iodide (PI) to demonstrate that Si cells are non-viable ( $n=3$ biological replicates). SSC, side scatter. $\mathbf{h}$, Tumour burden over time based on IVIS bioluminescence of FVB mice IP-injected on day 0 with either live (cancer challenged) or Si (vaccine only) BR5-Akt-Luc2 cells ( $n=3$ per group; $P=0.0013$ day 13, Holm-Šidák multiple comparisons; individual animal curves in Supplementary Information). ${ }^{\star} P<0.05,{ }^{\star \star} P<0.01,{ }^{\star \star \star} P<0.001$.

or paraformaldehyde-fixed tumour cells using flow cytometry and Cell Trace Far Red (CTFR)-labelled cells. Si tumour cells bound with $\mathrm{CpG}$ and MPL had a 9-fold increase in uptake compared with live or fixed tumour cells (Fig. 2c). The increase in uptake of Si vaccine cells is based on the ability of TLR ligands to specifically promote phagocytosis in both murine and human cells through induction of a phagocytic gene program, with TLR9 being the strongest promoter $^{29}$. Activation of TLRs was also supported by an increase in CD80 expression by DC (Extended Data Fig. 2b).

To confirm DC internalization of intact cancer cells, the Amnis Imagestream was used to image and quantitate vaccine uptake. After $24 \mathrm{~h}, 64 \%$ of $\mathrm{Si}$ vaccine cells were internalized by BMDC in vitro (Fig. $2 \mathrm{~d}$ ). In tumour-bearing mice, the majority of $\mathrm{Si} \mathrm{vac}$ cine cells administered intraperitoneally were localized to filtering (spleen and liver) and lymphatic tissues (Extended Data Fig. 2c). The majority of vaccine, which was both free and cell-internalized, was located in CD11c-rich regions (milky spots) of the omentum (Extended Data Fig. 2d).

Finally, to assess tumour-specific antigen presentation in the context of MHC I, we used the ID8ova cell line that expresses the model antigen ovalbumin. Ova peptide (SIINFEKL) presentation on MHC I by DC was assessed by flow cytometry analysis after $72 \mathrm{~h}$ co-culture with Si ID8ova vaccine cells. This time point was selected on the basis of previous work demonstrating optimal target antigen presentation with mesoporous silicon microparticles ${ }^{16}$. These experiments showed that DC processing of a model antigen and peptide presentation was superior using Si vaccine cells compared with irradiated cancer cells (Fig. 2e).

Si surface modified tumour cells generate tumour-specific immunity in vivo. To evaluate the immunogenicity of $\mathrm{Si}$ vaccine cells in vivo, albino C57BL/6 mice were injected with Si ID8ova 

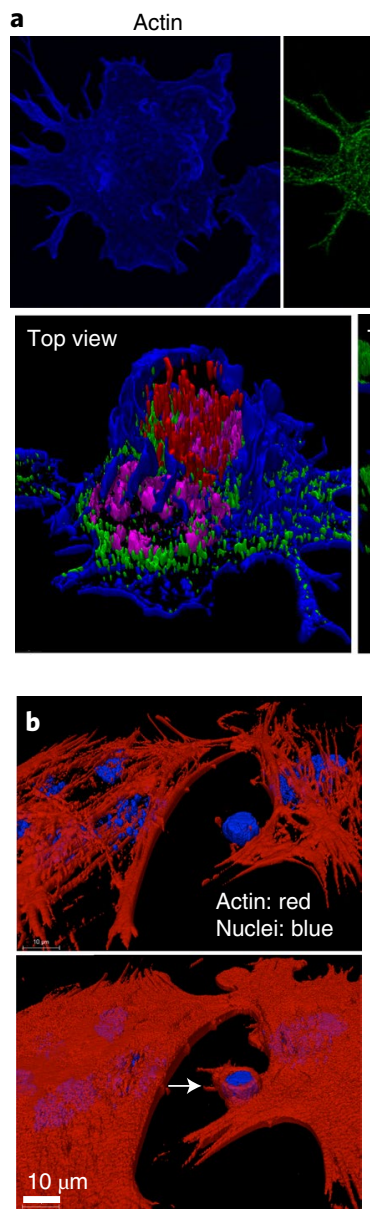

Tubulin
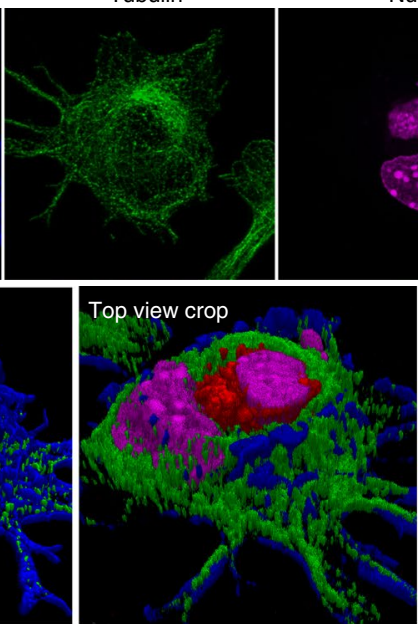

d

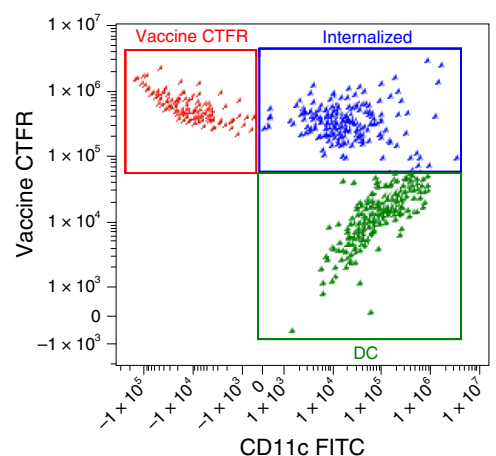

Vaccine cell
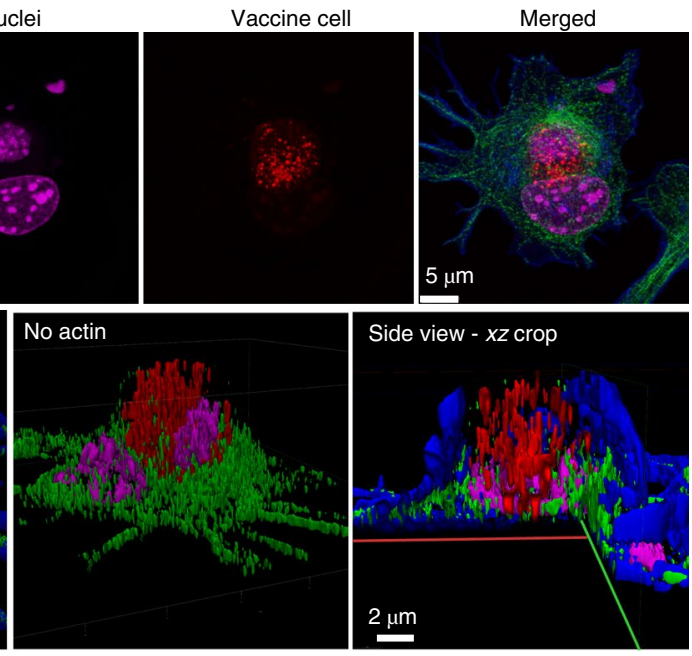

Side view $-x z$ crop

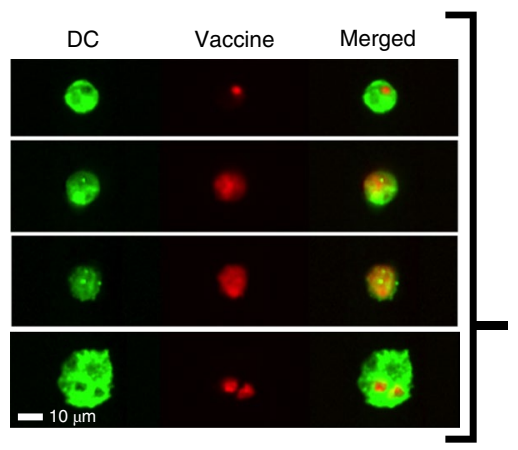

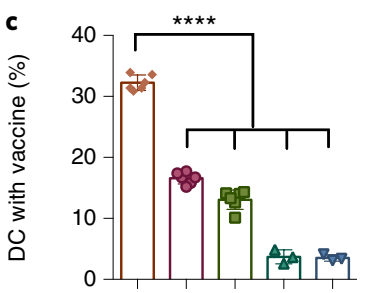
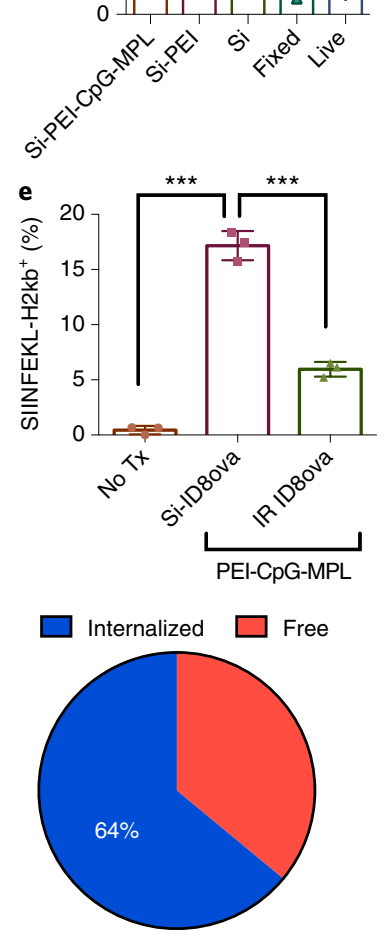

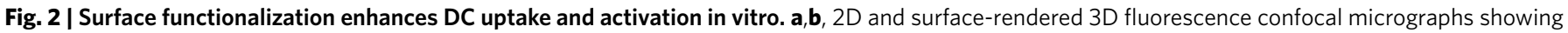
internalization and intracellular location of Si tumour cells following $1 \mathrm{~h}$ incubation with GM-CSF-matured BMDC. Tumour cells were pre-incubated with fluorescent nanoparticles before silicification to distinguish internalized vaccine cells from DC (a). Actin fluorescence is shown at two threshold levels for inside and surface views (b). The white arrow points to active phagocytosis. c, Flow cytometry analysis of DC uptake of Si BR5-Akt cells presenting no TLR ligands (Si), PEI or PEI-CpG-MPL ( $n=3$ to 6 biological replicates; unpaired two-tailed parametric $t$-tests; centres 32, 17, 13, 4 and 4; s.d. error bars). d, Amnis Imagestream imaging cytometry analysis of vaccine (CTFR, red) internalization by BMDC (5:1 for 24 h; anti-CD11c mAb FITC, green) ( $n=3$ ). e, Flow cytometry analysis of MHC I presentation of tumour antigen (SIINFEKL-H2Kb) on DC $72 \mathrm{~h}$ after addition of ID8ova vaccine cells or control irradiated ID8ova cells ( $n=3$ biological replicates; unpaired two-tailed parametric $t$-tests; centres $0.4,17.2$, and 6.0 ; s.d. error bars). ${ }^{\star \star \star} P<0.001$, ${ }^{\star \star \star \star} P<0.0001$.

vaccine cells. Three weeks later, mice were challenged intraperitoneally with live tumour cells. Tumour burden was monitored on the basis of bioluminescence with IVIS Spectrum imaging and quantified in photons per second ( $\mathrm{p} \mathrm{s}^{-1}$; Fig. $\left.3 \mathrm{a}\right)$. Si vaccine cell treated mice displayed complete blockade of tumour engraftment in contrast to sham PBS (no treatment $(\mathrm{Tx})$ ) or Si tumour cell treated mice, which showed partial resistance to tumour growth ( $n=10$ per group). To obtain a quantitative measure of cellular immune response, the enzyme-linked immunospot (ELISpot) was used to detect interferon (IFN) $\gamma$ production at the single-cell level as an indicator of antigen specific T-cell number ${ }^{30}$. Peritoneal immune cells from C57BL/6 mice vaccinated with Si ID8ova vaccine cells were stimulated with ovalbumin for $19 \mathrm{~h}$, and IFN $\gamma$ colorometric spots were counted. There was a 4.6-fold increase in IFN $\gamma$-producing $\mathrm{T}$ cells from vaccinated mice compared with sham PBS treated mice (Fig. 3b).

A similar survival benefit was seen using the BR5-Akt tumour model. Notably, in these experiments, antigen specificity was confirmed using vaccination with TLR agonist-coated mesoporous silica nanoparticles (MSN) or Si leukocytes as controls. Additional controls were sham PBS, Si tumour cells or oxidized tumour cell lysate, the latter including TLR agonists. All injections were IP (single dose on day 21), with the addition of subcutaneous (SC) administration of 1 versus 2 doses of vaccine. Tumour cell bioluminescence supported complete blockade of tumour engraftment in all IP and SC vaccinated mice (Fig. 3c). In contrast, TLR agonist-coated MSN or Si leukocyte treated mice showed progressive tumour growth requiring euthanization by day 30 , confirming that tumour cell, and presumable tumour antigens, are required for immune protection. Also, tumour cell lysate combined with TLR ligand was insufficient to protect mice, showing that the intact tumour cell with TLR agonist is needed.

Therapeutic vaccination in vivo results in durable survival benefit. The ability of vaccination to clear pre-existing tumours was evaluated in FVB mice with BR5-Akt-Luc2 tumours. First, an optimal route of administration, dose and schedule were established to optimize tumour clearance and survival (Extended Data Fig. 3 and Supplementary Fig. 6). Subsequently, this optimal protocol using Si vaccine cells was directly compared with an irradiated tumour cell vaccine that has been advanced to clinical trials ${ }^{31}$. Results from these studies showed that $\mathrm{Si}$ vaccine cells completely eliminated existing peritoneal tumours with clear superiority over the irradiated tumour cell vaccine (Fig. 4a,b). Modification of irradiated cells 
a
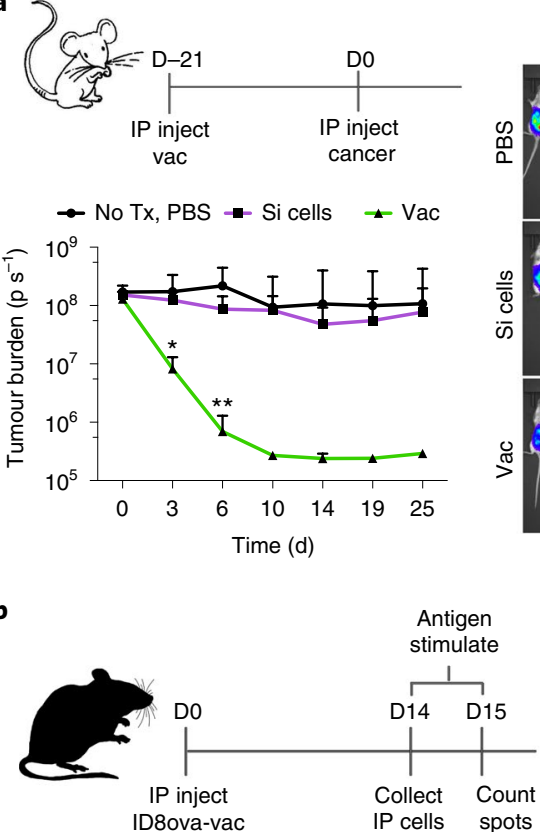
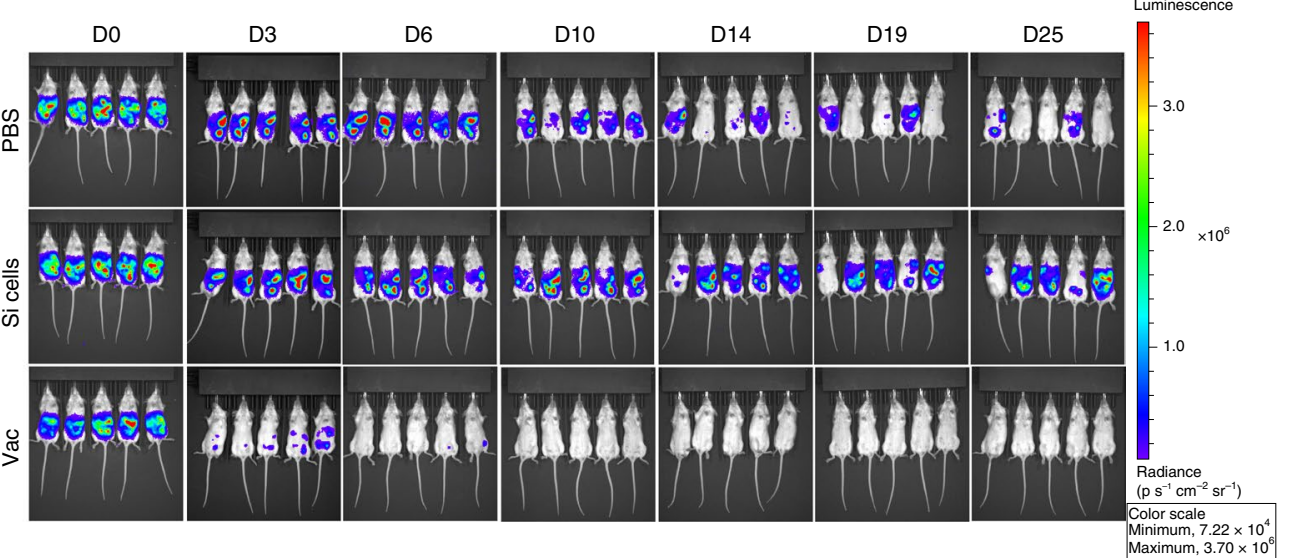

C
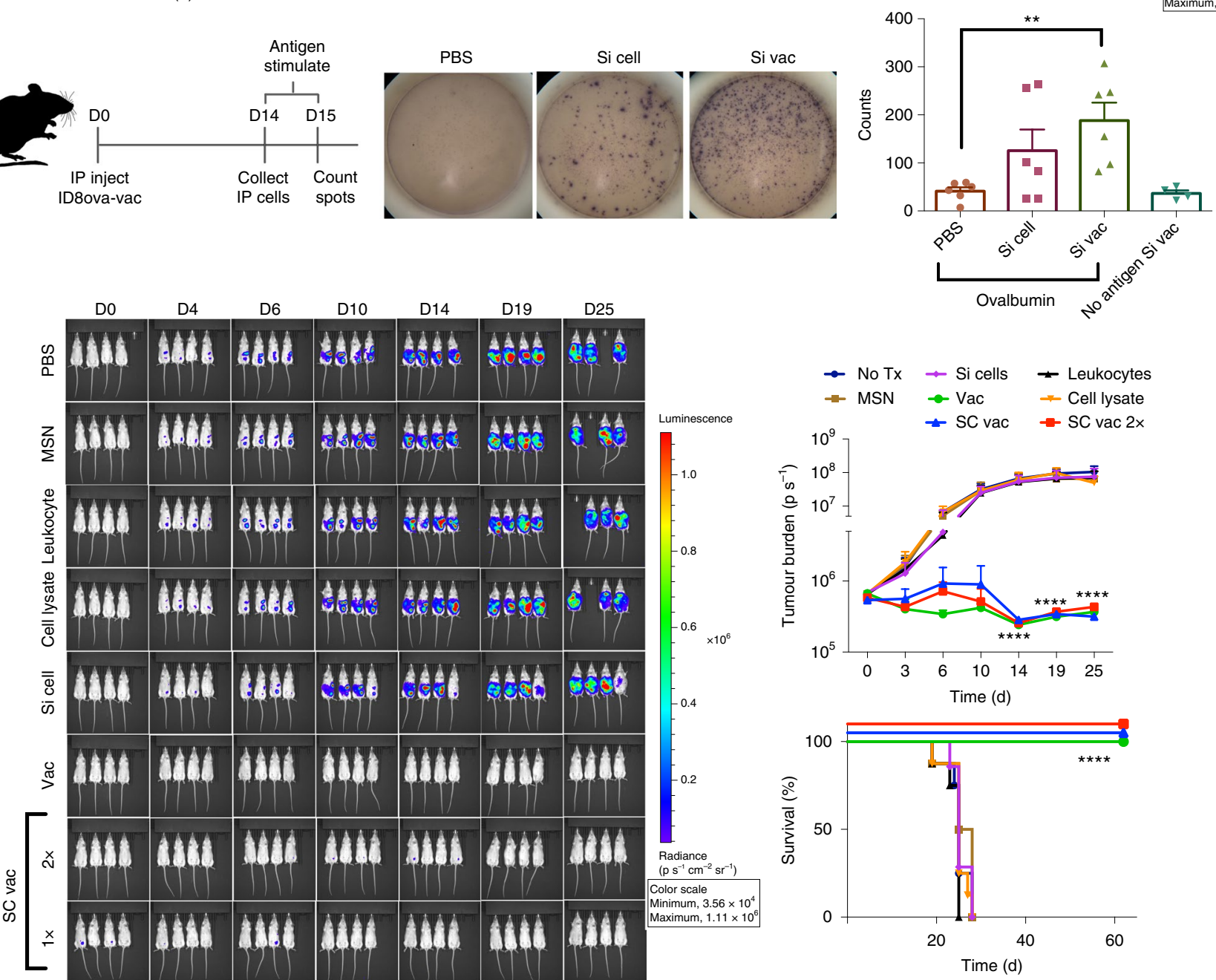

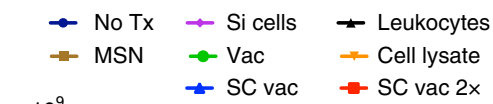
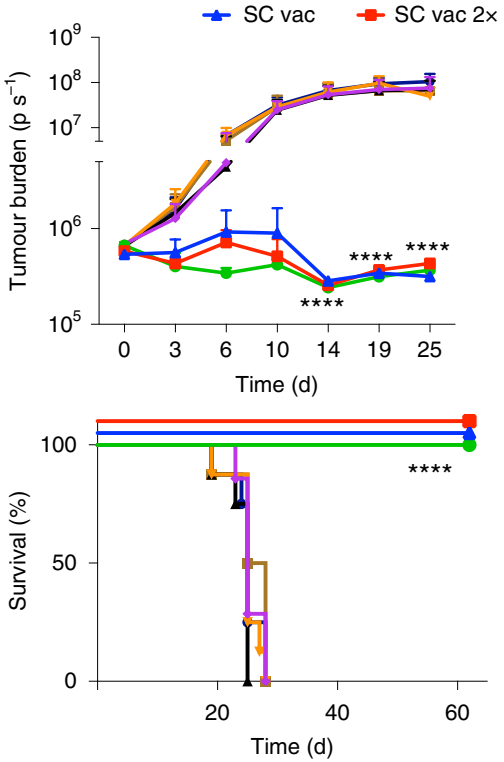

Fig. 3 | Treatment with Si cells induces a protective immune response in vivo. a, Tumour engraftment was evaluated in albino C57BL/6 mice challenged with ID8ova-Luc2 cells $21 \mathrm{~d}$ after IP administration of vaccine ( $n=10$ per group; no Tx versus vaccinated $P=0.03$ and $P=0.005$ at days 3 and 6 , respectively; Holm-Šidák multiple comparisons). b, IFN $\gamma$ ELISpot of vaccine or Si-cell experienced or naive peritoneal T cells stimulated with ovalbumin for $24 \mathrm{~h}$ ex vivo ( $n=6$ biological replicates; $P=0.003$ unpaired two-tailed $t$-tests; centres 41, 126, 188 and 37; s.e.m. error bars). c, Antigen specificity was also evaluated in FVB mice ( $n=8$ per group) challenged with BR5-Akt-Luc2 cells $21 \mathrm{~d}$ after IP injection with vaccine cells, no antigen control MSN-PEI, no antigen control leukocytes (with PEI) or oxidized cell lysate, all containing CpG and MPL ( $n=8$ per group; Holm-Šidák multiple comparisons). Therapeutic benefit of IP versus SC vaccination was also evaluated ( $n=4$ per SC group). Tumour burdens are presented graphically and as an IVIS image for each study. Individual animal curves in Supplementary Information. ${ }^{\star} P<0.05 ;{ }^{* \star} P<0.01 ;{ }^{\star \star \star \star} P<0.0001$.

with PEI, CpG and MPL improved performance, but even with these changes, the irradiated tumour cell vaccine was inferior to $\mathrm{Si}$ vaccine cells.
Vaccine can be dehydrated without loss of efficacy. In these comparisons, additional advantages of cell silicification were identified. Specifically, silicification enables cancer cells to be dehydrated and 

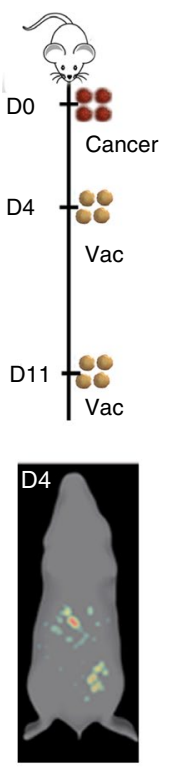
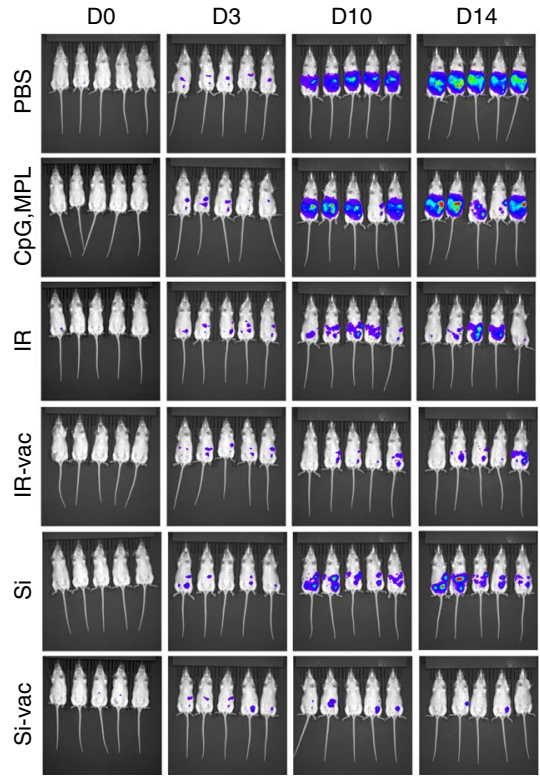

b
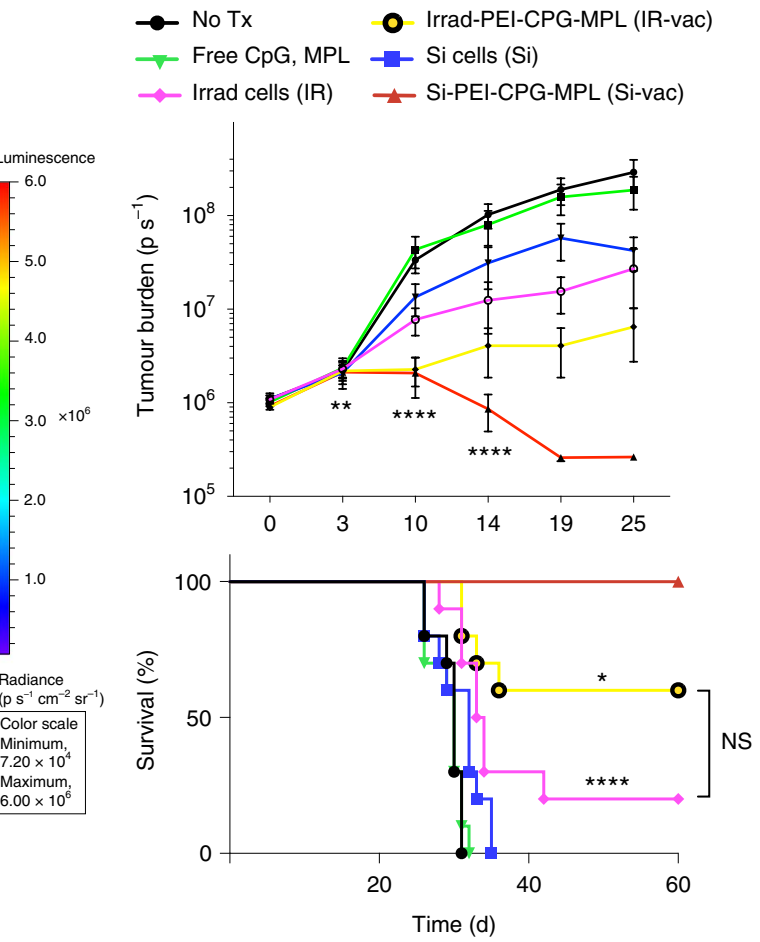

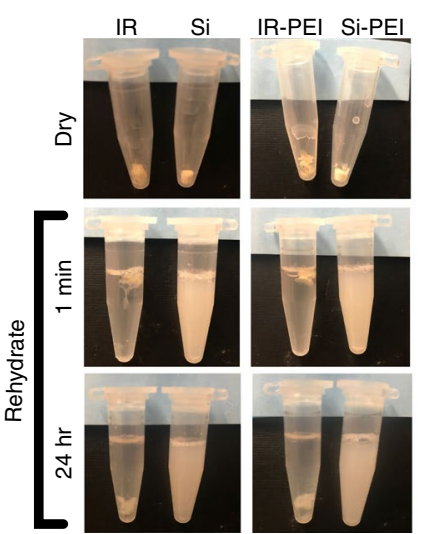

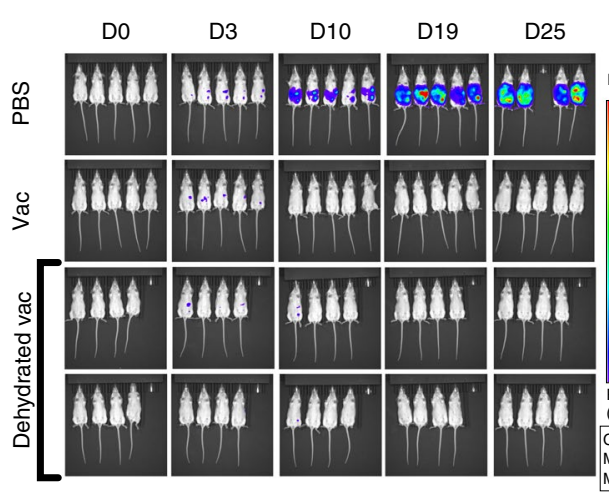

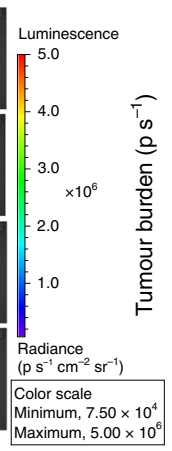

Fig. 4 | Therapeutic vaccination clears pre-existing tumours. a, Diagram of treatment schedule and tumour burden (IVIS 2D and 3D images) in FVB mice IP injected with BR5-Akt-Luc2 tumour cells, followed by treatment with free adjuvant (CpG, MPL) or vaccination with Si or irradiated (IR) cancer cells, with and without adjuvant. b, Tumour burden ( $\mathrm{p} \mathrm{s}^{-1} ; P=0.0012$ and 0.0017 for no Tx versus Si-Vac and IR-Vac, respectively; Holm-Šidák multiple comparisons) and Kaplan-Meier survival curves ( $n=10$ per group; $P=0.03$ for Si-Vac versus IR-Vac; log-rank Mantel-Cox). c, Photographs of IR or Si ( + - PEI) cancer

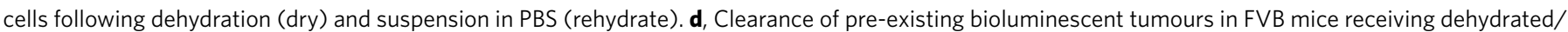
rehydrated vaccine IP on days 4 and 11 as compared with no treatment (control PBS) or fresh (non-dehydrated) vaccine ( $n=4$ to 8 per group; Holm-Šidák multiple comparisons). Individual animal curves in Supplementary Information. ${ }^{\star} P<0.05,{ }^{\star \star} P<0.01,{ }^{\star \star \star \star} P<0.0001$.

stored at room temperature (Fig. 4c). Following rehydration, the Si cells can be coated with TLR ligands or other immune agonists. Notably, the therapeutic efficacy of vaccination was not diminished in mice injected with rehydrated $\mathrm{Si}$ vaccine cells that had been stored at room temperature for two weeks compared with mice vaccinated with fresh modified Si vaccine cells (Fig. 4d). In contrast, irradiated cell vaccines did not survive dehydration, remaining aggregated after attempts at rehydration. The ability to store cellular tumour vaccines at room temperature is a significant advance that is expected to facilitate production and expand access to personalized cancer immune therapy.

Vaccination promotes effector function of tumour-associated lymphocytes. Vaccinated mice had a significant increase in the total number of $\mathrm{CD}^{+}$and $\mathrm{CD}^{+} \mathrm{T}$ cells and a marked increase in the proportion of effector memory cells in the peritoneal tumour environment (Fig. 5a,b, Extended Data Fig. 4 and Supplementary Figs. 7 and 8). Notably, Si tumour cell vaccination reduced the mean CD4/CD8 ratio from 6.0 to 1.5 (Fig. 5c, ranges $4.5-8.7$ and 1.1-1.9 for no Tx and vaccinated groups), which is associated with improved outcomes in patients with ovarian cancer ${ }^{32}$. In addition, vaccination significantly reduced the percentage of suppressive regulatory $\mathrm{CD}^{+} \mathrm{T}$ cells (Fig. $5 \mathrm{~d}$ ) while increasing $\mathrm{T}_{\mathrm{H}} 1$ polarization among $\mathrm{CD}^{+} \mathrm{T}$ cells (Fig. 5e). Increased levels of interleukin (IL)-2, IFN $\gamma$ and tumour-necrosis factor (TNF) $\alpha$ production by both $\mathrm{CD}^{+}$ and $\mathrm{CD}^{+} \mathrm{T}$ cells were observed following ex vivo stimulation (Fig. $5 e$ and Supplementary Fig. 9). Ascites fluid TNFo was also elevated following vaccination (Fig. 5f).

To assess for the induction of adaptive immunity in response to vaccination, the cytotoxic capacity of peritoneal $\mathrm{CD}^{+} \mathrm{T}$ cells isolated from vaccinated mice were tested ex vivo. These experiments showed enhanced cancer cell killing compared with CD8 ${ }^{+}$ 


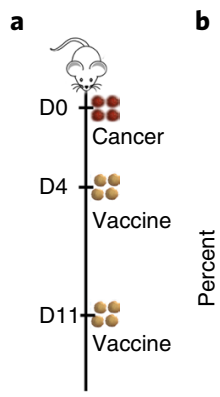

D25 cytometry (b-e) Dx luminex (f) D33 AT CD8 ${ }^{+}$cells $(\mathbf{h})$

b
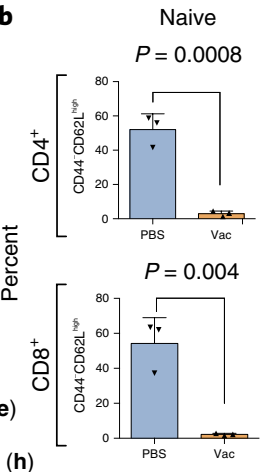

Central memory
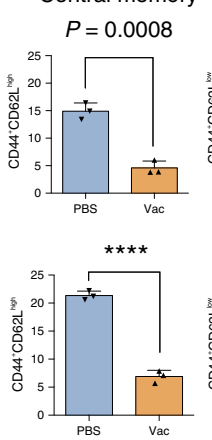

\section{Effector memory}
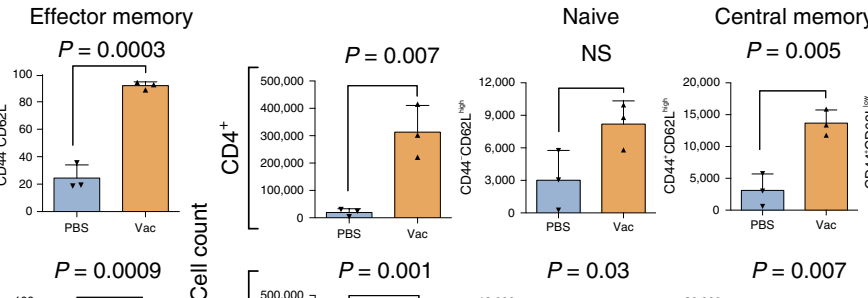

tral memory Effector memory

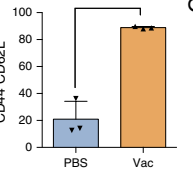

$P=0.03$

$P=0.007$

$P=0.008$
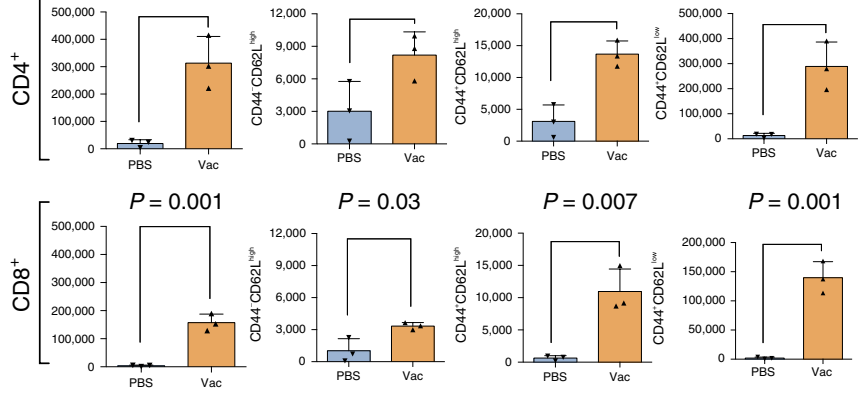

$P=0.001$

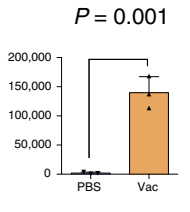

PBS Vac

d $\mathrm{CD}^{+}$
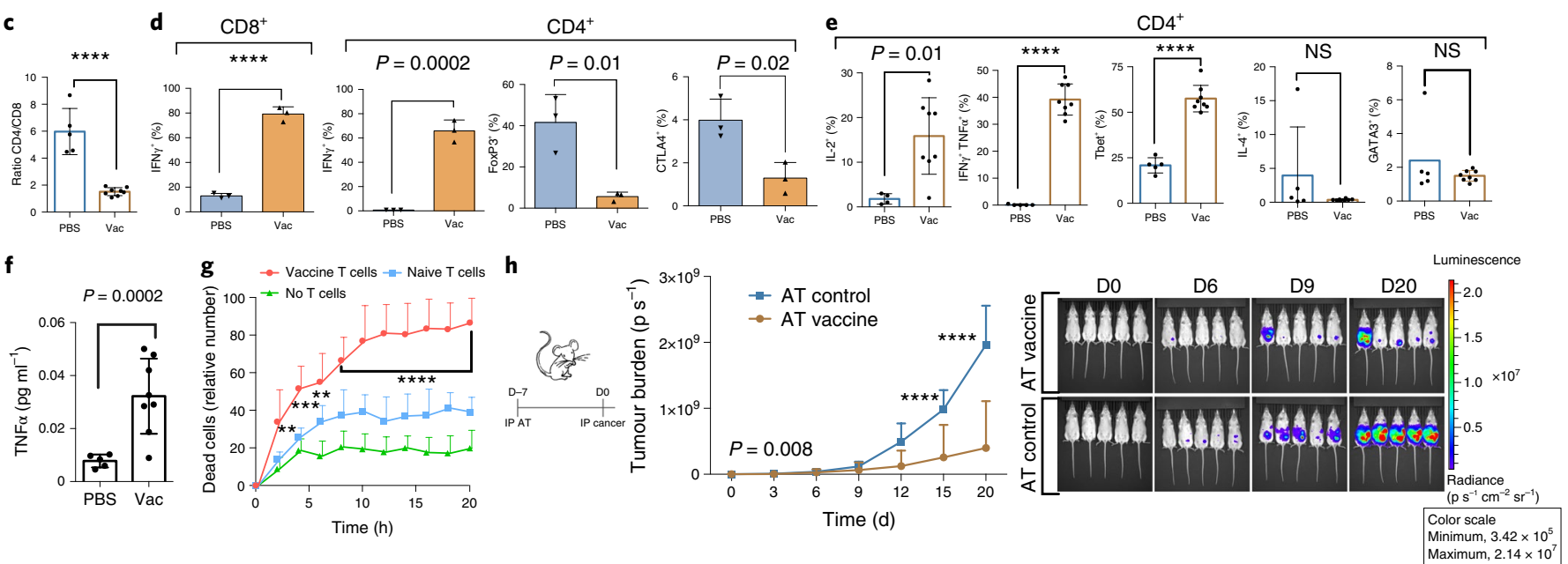

Fig. 5 | Therapeutic benefit of vaccination is associated with significant changes in tumour-associated lymphocytes and cytokines. a-e, Flow cytometry was used to define changes in peritoneal T-cell type and activation status following vaccination. Female FVB mice were IP injected with BR5-Akt-Luc2 cancer cells on day 0, vaccinated on days 4 and 11 with BR5-Akt vaccine cells ( $\mathrm{Si}$ Vac) or vehicle PBS (no Tx), and peritoneal fluid/wash was collected for analysis on day 25 (unpaired two-tailed parametric $t$-test, s.d. error bars). $\mathbf{a}$, Timeline. b, Percent and number of IP CD4+ and CD $8^{+} T$ cells with naive $\left(\mathrm{CD} 44-\mathrm{CD} 62 \mathrm{~L}^{\text {high }}\right)$, central memory $\left(\mathrm{CD} 44^{+} \mathrm{CD} 62 \mathrm{~L}^{\text {high }}\right)$, and effector memory (CD44 $\left.{ }^{+} \mathrm{CD} 62 \mathrm{~L}^{\text {low }}\right)$ phenotypes $(n=3$ per group; percent change centres $\mathrm{CD} 4$ : naive 52, 3, central memory 15, 5, effector memory 24, 92; CD8: naive 54, 2, central memory 21, 7, effector memory 21, 89; cell count centres CD4: 19,411, 313,142 , naive 3,017, 8,194, central memory 3,114, 13,680, effector memory 13,124, 289,001; CD8: 3,566, 157,313, naive 1,022, 3,339, central memory 637, 10,957 , effector memory 1,886, 139,802). c, Ratio of peritoneal CD4/CD8 cells $(n=5-8$, centres $6,1.5)$. d,e, Percent of CD4 ${ }^{+}$and CD8 ${ }^{+}$cells expressing activation markers ( $n=3$ per group; IFN $\gamma$ centres CD8 13, 79; CD4 0.7, 66); regulatory T-cell markers FoxP3 $(n=3$ per group; centres 42,6$)$ and CTLA4 ( $n=3$ per group; centres 4,1$), \mathrm{T}_{H} 1$ surface markers ( $n=4$ to 8 per group; centres IL-2 2,16; IFN $\gamma /$ TNF $\alpha$ 0.1, 39; and IL-4 4, 0.4) and transcription markers ( $n=5$ to 8 per group; centres Tbet 21, 58, GATA3 2.4, 1.5). f, Luminex cytokine analysis of ascites TNF $\alpha(n=8$ per group, centres $0.01,0.03)$. g, Cell death (YOYO- $3^{+}$) in co-cultures containing peritoneal CD8 $8^{+} \mathrm{T}$ cells from naive (untreated) or vaccinated (day 57) mice imaged for $20 \mathrm{~h}$ using the IncuCyte Live Cell Imaging System $(n=6 ; P=0.005,0.0003$ and 0.003 at 2, 4 and $6 \mathbf{h})$. h. The existence of local memory T cells was evaluated by adoptive transfer (AT) of CD8-enriched peritoneal cells from vaccinated mice to naive mice, with IP tumour challenge $24 \mathrm{~h}$ post vaccination with BR5-Akt-Luc2 cells $(n=10$ per group; Holm-Šidák multiple comparisons; individual animal curves in Supplementary Information). ${ }^{\star \star} P<0.01,{ }^{\star \star \star} P<0.001,{ }^{\star \star \star \star} P<0.0001$.

T cells from naive mice (Fig. $5 \mathrm{~g}$ ). The induction of an anti-tumour T-cell response in vivo following vaccination was evaluated with adoptive transfer experiments. Peritoneal $\mathrm{CD}^{+}$cells $\left(2 \times 10^{5}\right.$, magnetically enriched) collected from vaccinated tumour-bearing mice were transferred to tumour-naive mice $24 \mathrm{~h}$ before tumour challenge. $\mathrm{CD}^{+}$cells from unvaccinated, tumour-naive mice were used as a negative control. Results from these experiments showed that tumour-associated $\mathrm{CD}^{+} \mathrm{T}$ cells from vaccinated mice protected recipients from tumour challenge, while adoptively transferred $\mathrm{T}$ cells from naive mice did not (Fig. 5h). Collectively, these results demonstrate that vaccination with $\mathrm{Si}$ modified cells elicits a tumour-specific T-cell response and protective immune memory.

Vaccination synergizes with platinum chemotherapy to clear established tumour. In our initial experiments, we treated mice at a time point at which they had small-volume disseminated tumour. This mimics the treatment of patients after cytoreductive surgery, which is a central component of ovarian cancer treatment. Because treatment of both primary and recurrent ovarian cancer also includes platinum-based chemotherapy, we tested whether Si tumour cell vaccine could synergize with cisplatin to enhance tumour clearance in the setting of bulky disease. In these experiments, treatment with cisplatin was delayed until day 9 after tumour challenge. Mice received $2 \mathrm{mg} \mathrm{kg}^{-1}$ cisplatin $\mathrm{IP}^{33}$, followed by Si vaccine cells on days 10 and 17 (Fig. 6a). Tumour burden was measured by bioluminescence. Results from these experiments provide evidence of therapeutic synergy with improved survival in the combination treatment group compared with either cisplatin or vaccination alone (Fig. 6 b-d). As seen with early time point therapy, the proportion of functionally activated T cells expressing IFN $\gamma$ and TNF $\alpha$ was elevated in vaccinated mice, with cisplatin also stimulating production of TNF $\alpha$ (Fig. 6d). 
a

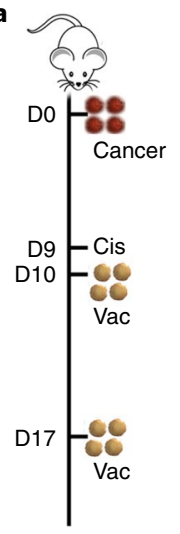

b

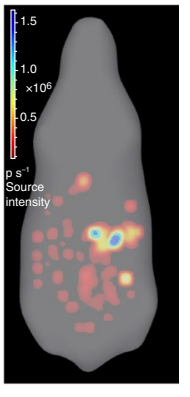

c

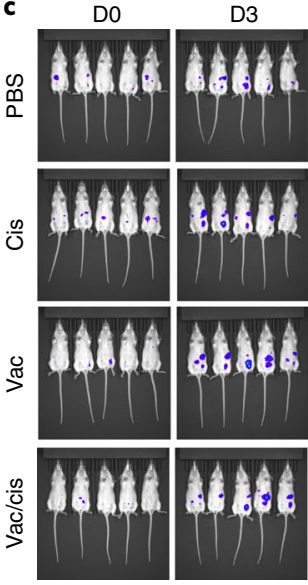

D10

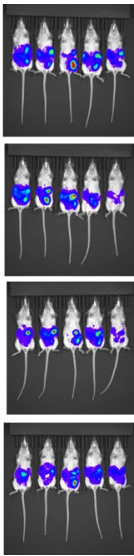

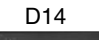

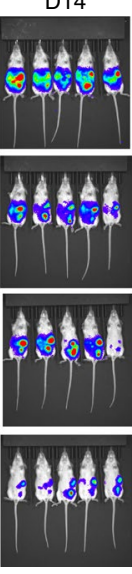

D19

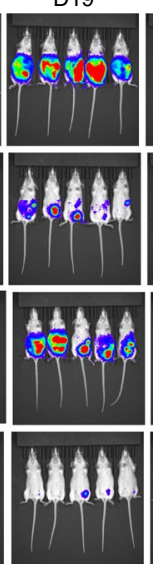

D25

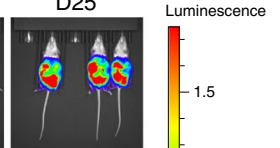

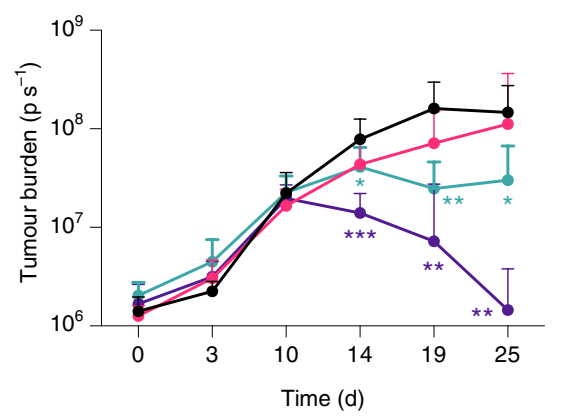

$\rightarrow$ No Tx

$\rightarrow$ Cis

$\rightarrow-\mathrm{Vac}$

$\rightarrow$ Cis + vac
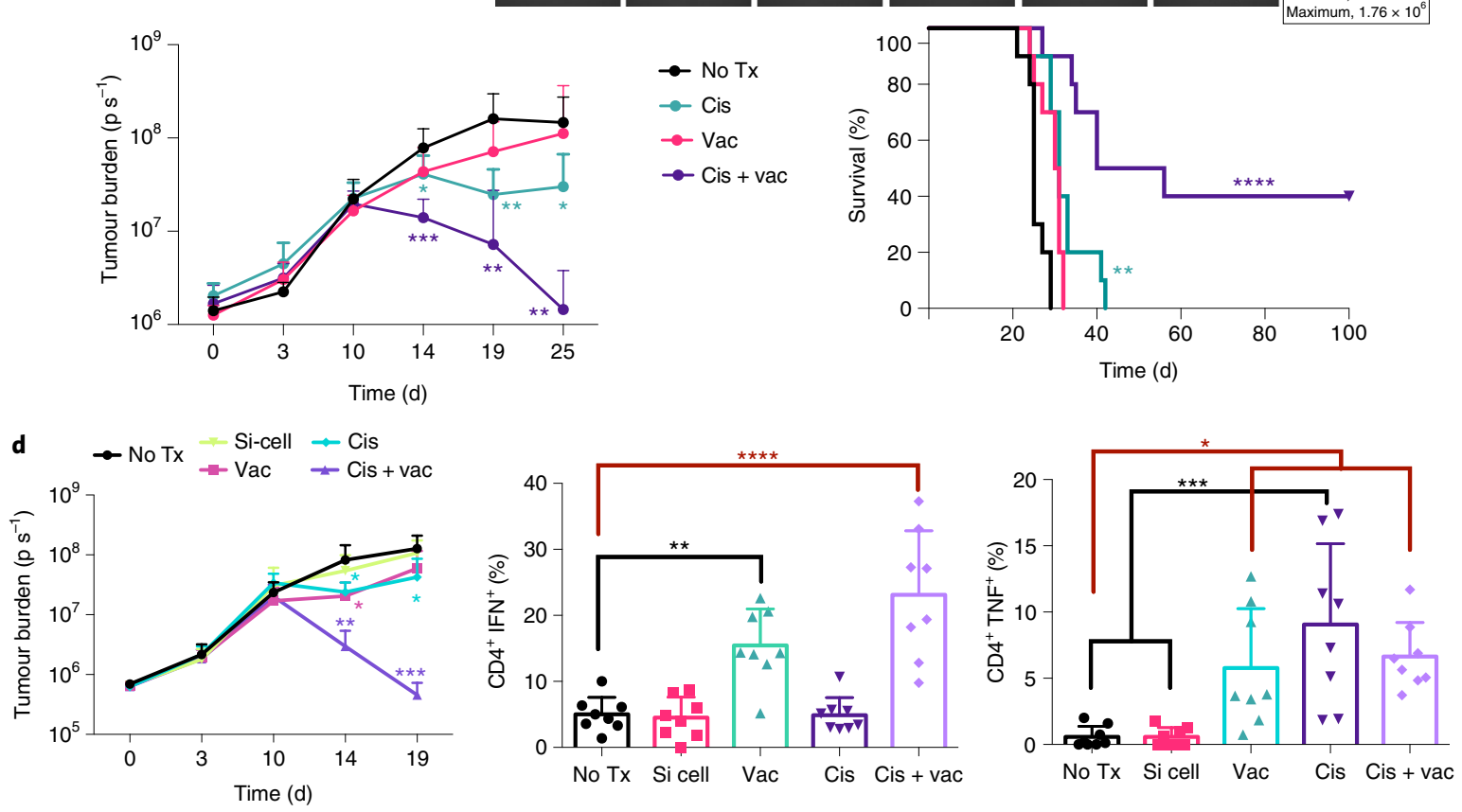

Fig. 6 | Combination cisplatin and vaccine therapy clears established peritoneal tumours and enhances survival in mice. a, Timeline. b, 3D IVIS image of a mouse on day 10 following IP injection with BR5-Akt-Luc2 cells. c, Tumour burden (no Tx versus cisplatin (cis) $P=0.04,0.006$ and 0.013 ; no Tx versus cis + vac $P=0.0005,0.003$ and 0.002; for days 14, 19 and 25, respectively; Holm-Šidák multiple comparisons) and Kaplan-Meier survival curves (no Tx versus cis $P=0.005$; log-rank Mantel-Cox) of BR5-Akt-Luc2 tumour-bearing FVB mice treated IP with cis (day 9) and/or vaccine (vac; days 10 and 17 ) ( $n=10$ per group). d, Tumour burden from replicate study (no Tx versus cis $P=0.02$ for days 14 and 19; no Tx versus vac $P=0.016$ day 14 , no Tx versus cis $+\operatorname{vac} P=0.003$ and 0.0006 for days 14 and 19). Flow cytometry analysis (day 20) of peritoneal T-cell activation status ( $n=6$ to 8 biological replicates; unpaired two-tailed parametric $t$-test, s.d. error bars; IFN $\gamma$ : no Tx versus vac $P=0.002$; TNF $\alpha$ : no Tx versus vac $P=0.049$, cis + vac $P=0.015$, and cis versus no Tx or Si cell (each $P=0.0004$ ); centres IFN $5,5,15,5,23$; TNF $\alpha 0.6,0.6,5.8,9.1,6.6$ ). Individual animal curves in Supplementary Information. ${ }^{\star} P<0.05,{ }^{\star \star} P<0.01,{ }^{\star \star \star} P<0.001,{ }^{\star \star \star *} P<0.0001$.

Ascites can be used for Si tumour cell vaccine development. Translating our findings to develop Si vaccines for cancer patients will require a source of autologous tumour cells. Clinically, ovarian cancer presents at late stages of disease when patients have metastases throughout the peritoneal cavity and accumulation of malignant ascites. To test whether tumour cells from ascites could be used for vaccine development, we collected ascites samples from mice with late-stage BR5-Akt tumours (Fig. 7a,b and Supplementary Fig. 9a,b). Tumour cells from ascites were enriched by filtration capture and Si using the protocol developed using cancer cell lines (Fig. 7b). Vaccination using Si mouse ascites tumour cells at the same dose and schedule as optimized previously showed equivalent efficacy as vaccination using $\mathrm{Si}$ vaccine cells grown in vitro (Fig. 7c). Secondary tumour challenge on day
36 was rapidly cleared (Fig. 7c). These results indicate that vaccine production using available tumour samples to create personalized vaccines is feasible.

To show vaccine production from cancer patients, ascites cancer cells were enriched by filtration capture (Fig. 7d), Si and coated with TLR ligands using PEI, MPL and human specific CpG 2006 (7909). Ascites CD11 $\mathrm{c}^{+} \mathrm{DC}$, enriched by loose attachment to plastic tissue culture dishes, internalized $96 \%$ of Si vaccine cells within $24 \mathrm{~h}$ (Fig. 7e). Vaccine treated DC displayed elevated CD86 expression within the same time frame (Fig. 7f). These results show that vaccination production is feasible from human ascites samples.

Vaccination with Si tumour cells is not associated with significant immune-related toxicity. In preparation for clinical translation, we 
a

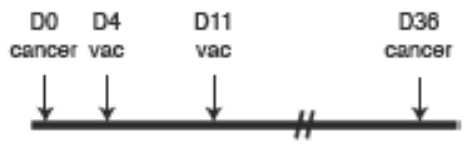

b
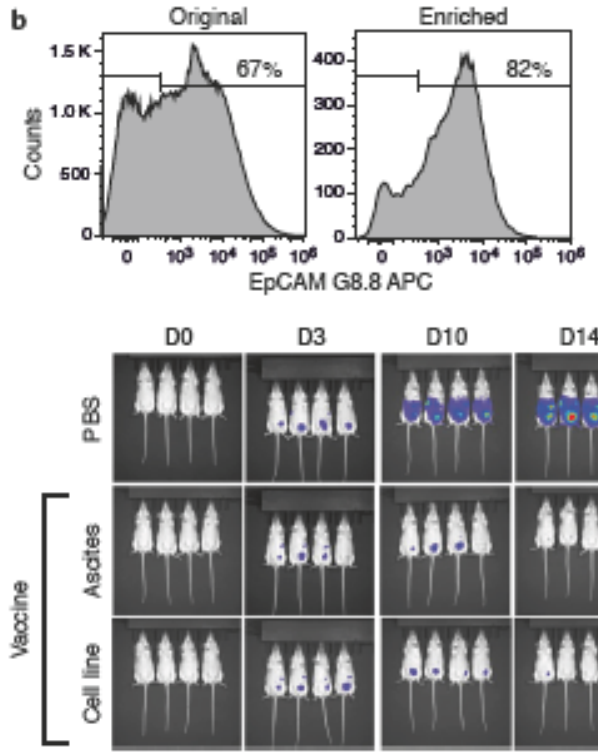

d
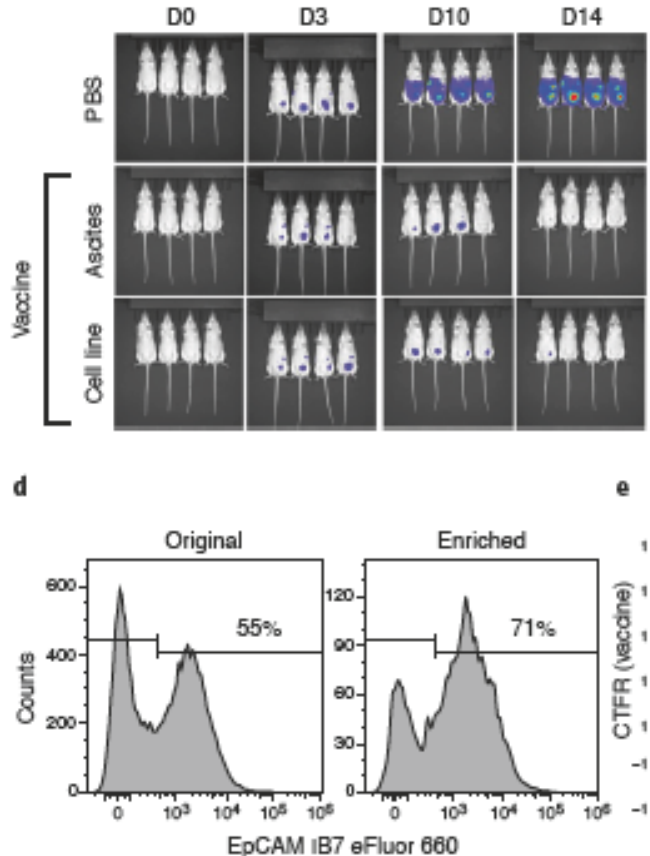

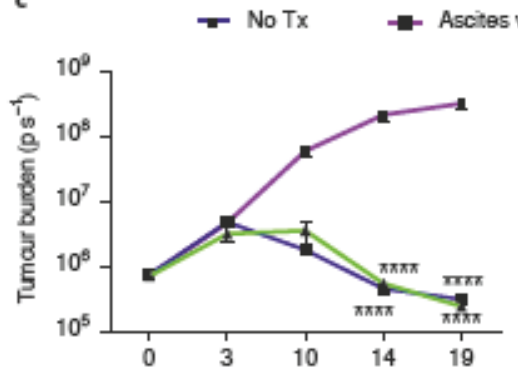

- Cell line vaccine
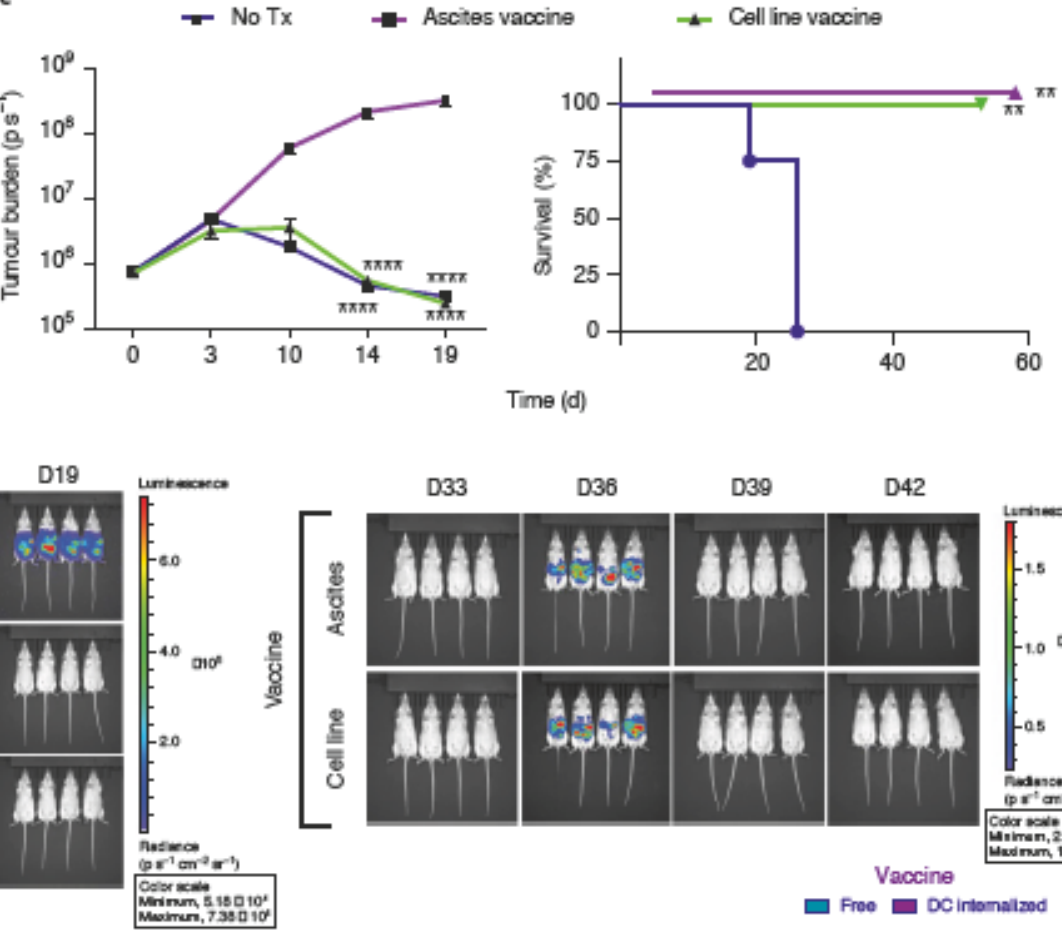

D36

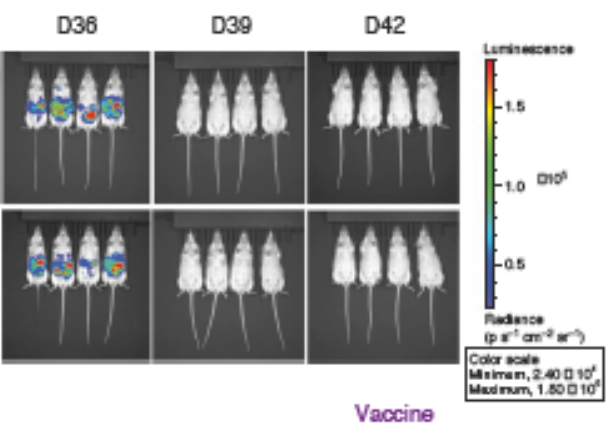

D42
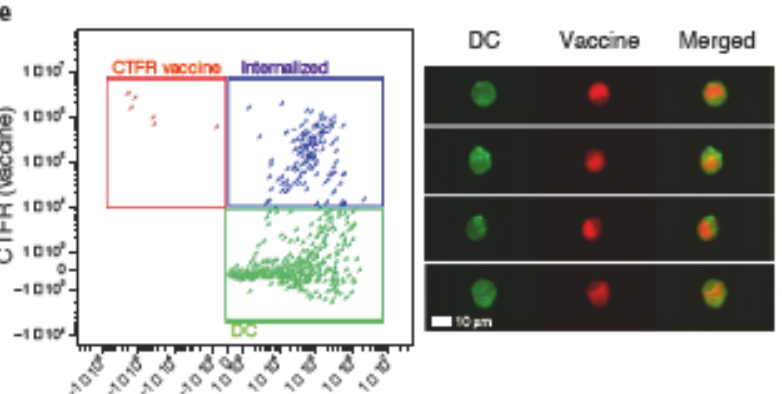

$\mathbf{f}$

Free DCintonalzod

CD11c FITC

Fig. 7 | Effective vaccine can be developed from ascites. a, Timeline. b, Flow cytometry analysis of mouse ascites cancer cell enrichment using filtration capture. c, Tumour burden (Holm-Šidák multiple comparisons; individual animal curves in Supplementary Information), Kaplan-Meier survival curve (log-rank Mantel-Cox) and corresponding IVIS spectrum bioluminescence images for mice IP vaccinated on days 4 and 11 with vaccine prepared using the BR5-Akt cell line (BR5 vac) or ascites tumour cells ( $n=4$ per group; curve comparison $P=0.0009$, no Tx versus $B R 5 P=0.01$, versus ascites $P=0.01$ ). To test immunological memory, vaccinated mice were re-challenged with BR5-Akt-Luc2 tumour cells on day 36. $\mathrm{d}$, Flow cytometry analysis of cancer cell enrichment from a human ascites sample. e, Imaging cytometry analysis of Si vaccine cell uptake by human ascites DC. f, Human DC activation by human Si vaccine cells based on CD86 expression $(n=3$ biological replicates; unpaired two-tailed parametric $t$-test; s.d. error bars, centres 29,55$)$. ${ }^{\star \star} P<0.01$, $\star \star \star \star P<0.0001$.

evaluated mice for any evidence of toxicity following vaccination. Histopathologic analysis performed by a board-certified veterinary pathologist showed pronounced necrosis in small residual islands of tumour in vaccinated mice associated with marked immune cell infiltration (Supplementary Fig. 10). Increased numbers of leukocytes were noted in peritoneal samples from vaccinated mice, but no evidence of suppurative peritonitis was found. No significant differences in complete blood count or electrolyte levels were observed in vaccine recipients compared with untreated controls (Extended Data Fig. 5a and Supplementary Fig. 11). Consistent with a T-cell mediated immune response, treatment of tumour-bearing mice with $\mathrm{Si}$ vaccine cells significantly increased blood lymphocytes (Extended Data Fig. 5b). Vaccination had no impact on renal or hepatic function (Extended Data Fig. $5 c$,d) and no vaccinated mice developed rash, alopecia, diarrhea or weight loss suggestive of treatment toxicity.

\section{Discussion}

We have described a modular vaccine for personalized immune therapy that shows durable therapeutic efficacy in high-grade serous ovarian cancer models. This strategy introduces substantial advantages over existing cell-based vaccines, including preserved tumour antigens, the opportunity for long-term dry storage, surface binding capacity for multivalent presentation of immune modulators, activation of both innate and adaptive immunity, potent therapeutic efficacy without evidence of toxicity, and simplified production and storage requirements for broader accessibility.

Cell silicification enables the ability to engineer cells to safely deliver target antigens and immune modulators. Because the silica surface is highly absorbent and readily binds adjuvants such as CpG and MPL, these cells acquire surface functionalization that can be exploited to direct specific immune responses. Coating $\mathrm{Si}$ cancer cells with TLR agonists induced innate and cellular immune 
activation, demonstrating enhanced internalization and processing by DC. Notably, DCs possess a unique mechanism for phagosome maturation, maintaining the phagosome at an alkaline $\mathrm{pH}$ of 7 to 7.5 in the first few hours after phagocytosis ${ }^{34}$. During this time, DCs recruit NOX2, leading to proton consumption by oxygen radicals and cell neutralization to facilitate peptide loading onto MHC molecules $^{35}$. These same conditions also favour siloxane bond ( $\mathrm{Si}-\mathrm{O}-\mathrm{Si}$ ) hydrolysis, facilitating silica dissolution ${ }^{36}$. Adsorption of PEI to silica further promotes silica dissolution at neutral and acidic $\mathrm{pH}$ due to $\mathrm{pH}$ buffering ${ }^{37}$. Our data show that DC activation in response to the vaccine is associated with the induction of tumour-specific adaptive immunity and protection against secondary tumour challenge. While these proof-of-principle experiments used TLR ligands as bound adjuvants for vaccine development, the Si cell surface can bind a broad array of molecules, presenting diverse opportunities for immune modulation and targeted therapy. Notably, the Si vaccine can be dehydrated and stored at room temperature. Upon rehydration, the choice of surface-bound adjuvant could be based on an individual patient's response to treatment or tailored for the immune landscape of a patient's tumour. In addition, the integration of antibodies or molecules that reverse inhibitory pathways in the tumour microenvironment would be expected to sustain the activation of cancer-specific $\mathrm{T}$ cells generated in response to the vaccine.

Importantly, women with ovarian cancer typically present with widely metastatic disease, often associated with abdominal ascites. Ascites fluid can be removed percutaneously with paracentesis or evacuated at the time of tumour debulking surgery. We have shown that ascites samples can be used to develop a highly effective Si vaccine, presenting a clinically feasible strategy for rapid vaccine development. This treatment paradigm presents an optimal opportunity for vaccination after surgical cytoreduction and frontline chemotherapy, when tumour burden is low. It is notable, however, that vaccination also enhances survival in the setting of bulky disease in combination with platinum agent, cisplatin, which is considered the backbone of treatment for ovarian cancer, including recurrent disease. These results show that vaccination can be effectively integrated into the established treatment protocols for this disease to enhance patient outcomes.

Prior approaches to creating personalized vaccines that have been tested in the clinic include DC vaccines based on ex vivo differentiation of peripheral blood monocytes, followed by pulsing with oxidized tumour cell lysate ${ }^{7,38}$, co-delivery of irradiated cells with BCG (https://www.cancer.gov/about-cancer/treatment/clinical-trials/ intervention/bcg-vaccine) or Cowpea Mosaic Virus ${ }^{39}$ or nanoparticles loaded with oxidized tumour cell lysate ${ }^{40}$. These processes can be laborious and costly $y^{7,41,42}$, or may rely on synthetic or heterogenous materials. In addition to low cost and rapid production (within $24 \mathrm{~h}$ ), an additional benefit of the Si cancer cell approach is the combination of tumour antigens and TLR ligands in a single construct. Nair-Gupta et al. ${ }^{43}$ demonstrated that TLR-loaded endosomes fuse with Rab11a positive MHCI storage vesicles in DC, enhancing cross presentation of antigens within the TLR ligand-containing endosomes. In summary, in addition to the Si vaccine outperforming and demonstrating markedly improved survival compared with a clinically tested irradiated tumour cell vaccine, the ability to dehydrate the vaccine has the potential to address a global need for versatile tumour vaccines with the potential to reduce existing disparities in access to cancer immune therapy. As a result, this technology would transform both the production and distribution of cancer vaccines, and facilitate the integration of immune therapy into cancer treatment protocols.

In summary, we have introduced a highly effective autologous cancer vaccine. The modular approach enables vaccine loading with unique molecules, either within or on the Si cell surface, to drive diverse responses, potentially across multiple tumour types. Vaccine delivery directly to the tumour microenvironment reprograms the suppressive milieu, supporting the development of anti-tumour immune responses and immunological memory. In addition, our approach simplifies vaccine production and distribution, facilitating the integration of immune therapy into current treatment protocols to improve survival outcomes.

\section{Methods}

Materials. Lipid A, monophosphoryl from Salmonella enterica serotype, tetramethyl orthosilicate, hydrochloric acid solution, sodium chloride, low molecular weight chitosan, poly-L-lysine, puromycin dihydrochloride, rhodamine $\mathrm{B}$ isothiocyanate mixed isomers and $10 \%$ buffered formalin were purchased from Sigma-Aldrich. CpG oligonucleotide 1826 and 2006 were purchased from Invivogen and PEI (25k linear) was purchased from Polysciences. Prolong Gold antifade mountant with DAPI, Alexa Fluor 488 alpha tubulin antibody phosphate-buffered saline (PBS) and RPMI 1640 were purchased from Thermo Fisher Scientific. Fetal bovine serum (FBS) was purchased from ATCC. EDTA trypsin solution $(0.05 \%)$, penicillin/streptomycin and rhodamine or Alexa Fluor 647 phalloidin were purchased from Life Technologies. Dulbecco's modified Eagle's medium (DMEM) was obtained from Caisson Labs. Cell Titer-Glo 2.0 Assay was purchased from Promega. Recombinant murine granulocyte macrophage colony stimulating factor (GM-CSF) was purchased from R\&D Systems. XenoLight D-luciferin potassium salt was purchased from Perkin Elmer. Reversible strainers (37 $\mu \mathrm{m}$ mesh) were purchased from STEMCELL Technologies.

Antibodies. CD11c FITC (HL3), CD11c FITC (B-ly6), CD326 (EpCAM, G8.8) APC, CD326 (M $\alpha$ H EpCAM IB7) eFluor 660, CD3 (17A2) APC-eFluor 780, CD4 (GK1.5) APC, CD8a (53-6.7) eFluor 450 and Alexa Flour 488, CD11b (M1/70) APC and FITC, CD11c (N418) PerCP-Cyanine5.5 and PECy7, CD40 (3/23) PE, CD44 (IM7) PerCP-Cyanine5.5, CD62L (L-selectin, MEL 14) FITC, CD152 (CTLA-4, UC10-4B9) PE and PerCp-Cy5.5, CD279 (PD-1, J43) PE-Cyanine7, FOXP3 (FJK-16s) PE, IFN gamma (XMG1.2) Alexa Fluor 488, MHC Class II (I A/I E) (M5/114.15.2) FITC, GATA-3 PerCP-eFlour 710 (TWAJ), TNF $\alpha$ PerCP-eFluor 710 (MP6-XT22), CD45R (B220) FITC, Fc receptor blockers (anti-CD16/CD32 (clone 2.4G2)), mouse IgG (31205), and LIVE/DEAD Fixable Aqua Dead Cell Stain Kit for $405 \mathrm{~nm}$ excitation were purchased from eBioscience/Thermo Fisher Scientific. IL-4 APC (11B11), CD152 (CTLA-4) PerCP, TIM3 (B8.2C12) APC and CD11c FITC (N418; Amnis BMDC and mouse tissues) were purchased from BioLegend. IL-2 PE (JES6-5H4) was purchased from BD Bioscience.

Cell lines and mouse models of ovarian cancer. The BRCA1-deficient BR5-Akt cell line, generated on an FVB background, was a kind gift from Dr Sandra Orsulic (Cedars-Sinai) ${ }^{44}$. The ID8ova cell line, generated from C57BL/6 ovarian epithelial cells, and transfected to express ovalbumin constitutively, was a gift from Dr George Coukos at the University of Pennsylvania ${ }^{45}$. Both ID8ova and BR5-Akt cell lines are syngeneic models of high-grade serous epithelial ovarian cancer. To monitor tumour burden using a bioluminescent tag, the cell lines were lentivirus transduced to constitutively express firefly2 luciferase. Cell lines were cultured in DMEM containing $10 \% \mathrm{FBS}$ and 100 units per $100 \mu \mathrm{g}$ penicillin/streptomycin at $37^{\circ} \mathrm{C}$ and $5 \% \mathrm{CO}_{2}$. Trypsin-EDTA was used to collect cells.

To prepare BMDC, bone marrow was collected from the femurs of female murine C57BL/6 or FVB mice using a $27 \mathrm{~g}$ needle and syringe to flush the marrow from the bone. RBC were lysed with $\mathrm{BD}$ lysis buffer as described by the vendor. Cells were cultured in 6-well plates ( $3 \mathrm{ml}$ per well) for 8-10 d in RPMI 1640 medium supplemented with $10 \%$ FBS, $100 \mathrm{mM} \beta$-mercaptoethanol, penicillin/ streptomycin and $10 \mathrm{ng} \mathrm{ml}^{-1}$ recombinant murine GM-CSF. Half of the media was replaced every 2-3 d with fresh media and cytokines. Human DCs were enriched from ascites samples by loose adhesion to plastic cell culture dishes.

Mice were purchased from Charles River or Jackson Laboratories and housed in a specific pathogen-free facility. All animal protocols were approved by the Institutional Animal Care and Use Committee (IACUC) at the University of New Mexico (Albuquerque, NM, USA). To generate consistent engraftment and predictable disease progression, $2 \times 10^{5}$ BR5-Akt-Luc2 or $1-5 \times 10^{6}$ ID8ova-Luc2 cells in $200 \mu \mathrm{l}$ PBS were administered by IP injection in 6-7 week old FVB or albino C57BL/ 6 female mice ${ }^{46}$. Mice were killed when moribund or when weight reached $30 \mathrm{~g}$ due to ascites accumulation. Mice were monitored and weighed every $2-3 \mathrm{~d}$. For studies that included SC tumours, female mice were injected with $200 \mu \mathrm{l}$ PBS containing $2 \times 10^{5} \mathrm{BR} 5$-Akt-Luc2 cells on the dorsal surface using isoflurane as an inhalation anaesthetic.

Cell silicification. BR5-Akt or ID8ova cells $\left(3 \times 10^{6}\right)$ as well as leukocytes obtained from RBC lysed FVB mouse spleen, or human ascites cancer cells enriched by filtration capture, were washed with PBS, followed by physiological saline (154 mM $\mathrm{NaCl}$ ), and then suspended in $1 \mathrm{ml}$ silicic acid solution containing $10 \mathrm{mM}$ TMOS, $100 \mathrm{mM} \mathrm{NaCl}$ and $1.0 \mathrm{mM} \mathrm{HCl}$ (pH 3.0), with scale up as needed. Optimization of conditions for biological use evaluated cell stability and dispersion following silicification in 5-100 $\mathrm{mM}$ TMOS and 100 versus $154 \mathrm{mM} \mathrm{NaCl}$. Following a 5-10 min incubation at room temperature, the cell suspension was transferred to $-80^{\circ} \mathrm{C}$ for $24 \mathrm{~h}$. Si cells were then washed with endotoxin-free water, followed by 
PBS. To compare silicon content with published cell silicification techniques, cells were also silicified at room temperature in silicic acid solution containing $100 \mathrm{mM}$ TMOS, $154 \mathrm{mM} \mathrm{NaCl}$ and $1.0 \mathrm{mM} \mathrm{HCl}\left(\mathrm{pH} \mathrm{3.0)}\right.$ for $24 \mathrm{~h}^{15}$.

Coating Si cells with cationic polymer. Si cells were made cationic using chitosan, poly-L-lysine or PEI. Si cells $\left(3 \times 10^{6}\right)$ were washed with water, followed by PBS, and then suspended in $1 \mathrm{ml}$ PEI $\left(0.2 \mathrm{mg} \mathrm{ml}^{-1}\right), 2 \mathrm{mg} \mathrm{ml}^{-1}$ chitosan or $1 \mathrm{mg}$ $\mathrm{ml}^{-1}$ poly-L-lysine in PBS. Following $10 \mathrm{~min}$ (or as indicated) rotation at room temperature, cells were washed twice with PBS and zeta potentials were evaluated.

Fluorescent PEI synthesis. PEI $(5 \mathrm{~g}, 0.2 \mathrm{mmol})$ was dissolved in $5 \mathrm{ml}$ ethanol and Cy3-NHS (10 $\mathrm{mg} \mathrm{ml}^{-1}$ in dimethylformamide (DMF), $150 \mu \mathrm{l}, 2 \mu \mathrm{mol}$ ) was added. The solution was rotated at $40^{\circ} \mathrm{C}$ for $4 \mathrm{~d}$. The mixture was concentrated using a rotavap, then $50 \mu \mathrm{LMF}$ was added to dissolve any unreacted dye. The mixture was centrifuged at $21,000 \times \mathrm{g}$ for $20 \mathrm{~min}$ and the isolated pellet was dissolved in ethanol and transferred to the rotavapor to remove DMF traces. After $1 \mathrm{~h}$, the PEI-Cy3 was dissolved in PBS at $0.5 \mathrm{mg} \mathrm{ml}^{-1}$.

Adsorption of TLR ligand to Si or irradiated cells. Si cells $\left(12 \times 10^{6}\right)$ with or without polymer coating were washed with PBS and then suspended in $25 \mu \mathrm{l}$ MPL ( $\left.1 \mathrm{mg} \mathrm{ml}^{-1}\right)$ in DMSO. After $10 \mathrm{~min}$ incubation at room temperature, Si-PEI-MPL or Si-MPL cells (or their chitosan counterparts) were washed with PBS by centrifugation at $2,000 \times \mathrm{g}$ for $5 \mathrm{~min}$ followed by suspension in PBS. Oligodeoxynucleotide 1826 adsorption followed a similar protocol using $20 \mu \mathrm{l}$ CpG $\left(2 \mathrm{mg} \mathrm{ml}^{-1}\right)$ in endotoxin-free water for every $12 \times 10^{6} \mathrm{Si}$ cells. For dual adsorption of MPL and CpG, CpG was introduced first for $10 \mathrm{~min}$, followed by the addition of MPL for an additional $10 \mathrm{~min}$. To quantitate ligand loading, unbound fluorescent TLR ligand was measured using a BioTek microplate reader with excitation/ emission at $470 / 560 \mathrm{~nm}$ for PEI-Cy3, and excitation/emission at $488 / 528 \mathrm{~nm}$ for CpG-FITC detection. MPL was quantified by absorption at $290 \mathrm{~nm}$ using a ThermoScientific NanoDrop 2000. Irradiated BR5-Akt cells were incubated with PEI, CpG and MPL using the same conditions optimized for Si cells.

Dehydration and rehydration of vaccine cells. Si or irradiated cells (with or without $\mathrm{PEI}$ ) were rinsed with PBS and then dried under vacuum at room temperature for $16 \mathrm{~h}$. Samples were stored at room temperature for $14 \mathrm{~d}$. Before use, cells were rehydrated in PBS with vortexing and coated with PEI, CpG and MPL.

Zeta-potential measurements. Zeta-potential measurements were performed using the Malvern Zetasizer Nano-ZS (Westborough) equipped with a $\mathrm{He}-\mathrm{Ne}$ laser $(633 \mathrm{~nm})$ and non-invasive backscatter optics. Cells were suspended in $5 \mathrm{mM} \mathrm{NaCl}$ solution with measurements performed using the monomodal analysis tool. All reported values correspond to the average of at least three independent samples.

Optical microscopy. For bright-field imaging, cells were suspended in the water or PBS and imaged using the Nikon eclipse TS 100 inverted microscope equipped with a Nikon digital-sight DS-L3 camera.

In vitro DC internalization of fluorescent Si cells. To image DC association with Si cells, BR5-Akt cancer cells were first incubated with fluorescent lipid-coated MSN labelled with Cy3 or DyLight 488 and presenting MPL for 4-24h. Tumour cells were then silicified using optimized conditions and surface-masked with TLR ligands (as indicated). DC were seeded onto glass coverslips in 6-well plates at a density of $5 \times 10^{5}$ cells per well and the next day, fluorescent $\mathrm{Si}$ vaccine cells were added and DC were incubated as indicated. DC were then washed with PBS and fixed with $4 \%$ paraformaldehyde for $15 \mathrm{~min}$ at room temperature, followed by overnight incubation at $4{ }^{\circ} \mathrm{C}$. The following day, cells were washed with PBS permeabilized with $0.1 \%$ Triton-X in PBS for $15 \mathrm{~min}$, blocked with $1 \%$ BSA for $20 \mathrm{~min}$, and then labelled with Alexa Fluor 647 phalloidin in 1\% BSA for $1 \mathrm{~h}$. After a final wash in PBS, coverslips were mounted on slides using Prolong Gold with DAPI. Images were acquired using a $63 \mathrm{X} / 1.4 \mathrm{NA}$ oil objective in sequential scanning mode using a Leica TCS SP8 confocal microscope.

DC uptake of Si cells was quantified using an Attune NxT flow cytometer (Thermo Fisher) or the Amnis ImageStream. Human ascites cancer cells or mouse BR5-Akt cells were stained with CTFR (1:4,000; Thermo Fisher) before silicification. Si cells, surface modified with TLR ligands as indicated, were co-cultured with Cell Trace Violet- (Thermo Fisher, flow cytometry) or anti-CD11c FITC- (Amnis; 1:1,000) labelled human or mouse DCs for 1-24h as indicated at a ratio of 5:1 (vaccine:BMDC), and then analysed by flow cytometry for double-positive cell populations or using the Amnis Imagestream. For Amnis analysis, a single cell population was gated on using a dot plot created using a bright-field laser (aspect ratio versus area), then focused bright-field cells were gated using a histogram of normalized frequency versus gradient root mean square. Lastly, a dot plot was created showing internalized and non-internalized cells (intensity of CTFR channel versus intensity of FITC channel).

T-cell killing assay. BR5- $A k t$ cells were seeded into a 96-well plate at $1 \times 10^{3}$ cells per well in $200 \mu \mathrm{l}$ cell culture medium, followed by overnight incubation at $37^{\circ} \mathrm{C}$ in $5 \% \mathrm{CO}_{2}$. Peritoneal T cells were purified using the Miltenyi Biotec CD8 $\mathrm{a}^{+} \mathrm{T}$-cell isolation kit from vaccinated (day 57)/tumour-challenged or naive FVB mice. $\mathrm{T}$ cells were added to cancer cells at a ratio of 5:1 and the cell impermeant nuclear dye YOYO-3 iodide ( $1 \mathrm{mM}$ in DMSO) was added at a dilution of 1:4,000. Cells were put in the IncuCyte Live Cell Imaging System (Sigma Aldrich) and imaged for $48 \mathrm{~h}$ with images acquired every $2 \mathrm{~h}$.

IFN $\gamma$ ELISpot. FVB mice were treated with PBS, Si cells or vaccine on day 0 and peritoneal cells were isolated on day 14 as previously described. The ELISpot assay was performed as described by the vendor (R\&D Systems), with $2 \times 10^{5} \mathrm{RBC}$ lysed peritoneal cells included per well per $100 \mu \mathrm{l}$ complete media. Ovalbumin was added at $15 \mu \mathrm{g}$ per well for $19 \mathrm{~h}$ at $37^{\circ} \mathrm{C}$. Spots were counted manually using a dissection microscope.

SEM and energy dispersive X-ray (EDX) analysis. Si tumour cells were suspended in $100 \%$ ethanol and then dropped onto $5 \times 5 \mathrm{~mm}$ glass slides. The glass slides were then mounted on SEM stubs using conductive adhesive tape (12 mm OD PELCO Tabs). SEM and EDX images were acquired under high vacuum at 7.5k using a FEI Quanta 3D Dualbeam FIB-FEGSEM with EDAX SDD EDS detector (Thermo Fisher).

ICP-OES. ICP-OES was used to measure Si concentration in Si cells. Cells $\left(20 \times 10^{6}\right)$ were washed with water and dried under vacuum for $7 \mathrm{~d}$ and then mineralized in aqua regia $\left(1: 3\right.$ mixture of ultrapure $\mathrm{HNO}_{3}$ and $\left.\mathrm{HCl}\right)$ with a Digi prep MS SCP Science block digester at $95^{\circ} \mathrm{C}$ for $4 \mathrm{~h}$. The digested samples were diluted and passed through $0.45 \mu \mathrm{m}$ filter. The concentration of silicon was then measured using a Perkin Elmer Optima 5300DV ICP-OES, with a detection limit of $<0.5 \mathrm{mg} \mathrm{l}^{-1}$. ICP-OES was calibrated with a five-point calibration curve. QA/QC measurements were also obtained to ensure quality results.

Si-cell degradation in simulated endosomal solution. Twenty million Si cells were suspended in $4 \mathrm{ml}$ simulated endosomal solution containing acetate buffer ( $\mathrm{pH}$ 5.2; Poly Scientific R\&D) and 20\% FBS at room temperature under rotation for $3 \mathrm{~d}$. After incubation, the cells were rinsed with water and then dried under vacuum for $7 \mathrm{~d}$. The silicon content of Si cells pre and post treatment was measured using ICP-OES.

Proliferation assays. Native and Si cells with or without PEI coating were assessed for cell growth using the CellTiter-Glo 2.0 assay. Briefly, cells were seeded at a density of 100,000 cells $\mathrm{ml}^{-1}$ in culture media in opaque white 96 -well plates. After $24 \mathrm{~h}$, CellTiter-Glo 2.0 reagent was added to each well, and following a 10 min incubation, luminescence was determined using a BioTek microplate reader. Percent cell viability was calculated relative to control, non-treated cells.

Preparation of MSN. A mixture of water $(100 \mathrm{ml})$, ethanol $(40 \mathrm{ml})$, sodium hydroxide $(\mathrm{NaOH}, 2 \mathrm{M}, 0.75 \mathrm{ml})$ and cetyltrimethylammonium bromide (CTAB, $0.640 \mathrm{~g}$ ) was heated to $70^{\circ} \mathrm{C}$ under vigorous stirring (750 r.p.m.) in a round-bottom flask immersed in an oil bath. Afterwards, tetraethyl orthosilicate $(1 \mathrm{ml})$ was added dropwise to the solution. The tetraethyl orthosilicate was allowed to undergo a series of hydrolysis condensation reactions for $2 \mathrm{~h}$ to yield silica CTAB-templated silica nanoparticles. The particles were then isolated by centrifugation $(2,000 \times \mathrm{g}$, $20 \mathrm{~min}$ ) and then washed with methanol three times. The surfactant removal was performed by suspending the nanoparticles in a solution of $0.45 \mathrm{~g} \mathrm{l}^{-1}$ ammonium nitrate in ethanol and stirring at $60^{\circ} \mathrm{C}$ for $20 \mathrm{~min}$. Finally, the template-free MSN were consecutively washed twice with water and ethanol, and stored suspended in ethanol. MSN $(0.5 \mathrm{mg})$ were rinsed twice with water and then suspended in $1 \mathrm{ml}$ PEI $\left(0.2 \mathrm{mg} \mathrm{ml}^{-1}\right)$ in PBS solution. After $10 \mathrm{~min}$ rotation at room temperature to allow PEI binding on the MSN surface, the MSN with PEI coating (MSN-PEI) were then rinsed with PBS twice. MSN-PEI $(0.87 \mathrm{mg})$ were suspended in $20 \mu \mathrm{l} \mathrm{CpG}$ $\left(2 \mathrm{mg} \mathrm{ml}^{-1}\right)$ in double distilled water solution. After $10 \mathrm{~min}$ incubation at room temperature, $25 \mu \mathrm{l} \mathrm{MPL}\left(1 \mathrm{mg} \mathrm{ml}^{-1}\right)$ in DMSO solution was added and incubated another $10 \mathrm{~min}$. MSN-PEI-CpG-MPL particles were then centrifuged at 20,000 r.c.f. for $5 \mathrm{~min}$ to remove extra free ligand, and then resuspended and stored in $1 \mathrm{ml}$ PBS. These conditions resulted in similar CpG and MPL dose content to vaccine cells.

In vitro DC functional studies. Bone marrow-derived or human ascites DCs were seeded in 12 -well plates at a density of $1 \times 10^{5}$ cells per well. After $24 \mathrm{~h}$, the media was removed and replaced with $2 \mathrm{ml}$ of fresh complete media supplemented with 100,000 Si-PEI-CpG-MPL (or irradiated PEI-CpG-MPL) ID8ova or human cancer cells for 24 or $72 \mathrm{~h}$ as indicated. Alternatively, DC were incubated with Si-LPS or $\mathrm{Si}-\mathrm{MPL}$ ID8ova cells for $72 \mathrm{~h}$. Irradiated cells were suspended in PBS in microfuge tubes at $3 \times 10^{6}$ cells per $\mathrm{ml}$ and exposed to $100 \mathrm{~Gy}$ using a Faxitron Multirad Irradiator at $22 \mathrm{rV}, 15 \mathrm{~mA}, 48 \mathrm{~Gy} \mathrm{~min}^{-1}$. DCs were collected using $3 \mathrm{mM}$ EDTA. The suspended cells were centrifuged, washed with PBS containing 1\% BSA and labelled with fluorescent antibodies specific for CD11c and either co-stimulatory molecules or SIINFEKL-H2kb. Cells were analysed using the Becton Dickinson Fortessa or Calibur flow cytometer.

Vaccination of mice with Si tumour cells. Tumour-bearing or naive female FVB or albino C57BL/6 mice were vaccinated intraperitoneally with irradiated (100 Gy using a Faxitron Multirad Irradiator at $225 \mathrm{~V}, 15 \mathrm{~mA}, 48 \mathrm{~Gy} \mathrm{~min}^{-1}$; or 
a Cs-137 gamma irradiator with a dose rate of $63 \mathrm{cGy} \mathrm{min}^{-1}$ ) or Si BR5-Akt (or BR5-Akt-Luc2 for vaccine viability analysis or ID8ova) cells (with TLR ligands as indicated) using doses of $3 \times 10^{4}, 3 \times 10^{5}, 3 \times 10^{6}$ or $3 \times 10^{7} \mathrm{Si}$ cells per mouse in $200 \mu \mathrm{l}$ of PBS at the indicated schedules. Control vaccines, all containing CpG and MPL, included no antigen MSN, Si leukocytes (splenocytes from naive mice) or oxidized cell lysate. Cell lysate was prepared by incubating BR5-Akt cells in $60 \mu \mathrm{M}$ hypochlorous acid in PBS for $1 \mathrm{~h}$ at $37^{\circ} \mathrm{C}$, followed by extensive PBS washing and five freeze-thaw cycles using dry ice and a $37^{\circ} \mathrm{C}$ water bath ${ }^{7,47,48}$. Alternatively, mice were vaccinated subcutaneously with $3 \times 10^{6} \mathrm{Si}$ BR5-Akt cells by scruffing the skin at the back of the neck and injecting an equivalent volume into the loose fold of skin. Mice that cleared all tumour cells based on IVIS Spectrum bioluminescent imaging were re-challenged with $2 \times 10^{5} \mathrm{BR} 5$ - $A k t$-Luc2 cancer cells at a later date, as indicated for each study. All control (no Tx) mice received sham PBS injections $(200 \mu \mathrm{l}$ per mouse). Single agent or combination therapy with cisplatin used IP administration of cis-diamineplatinum (II) dichloride (Sigma-Aldrich) on day 9 at $2 \mathrm{mg} \mathrm{kg}^{-1}$ in physiological saline.

Preparation of ascites-derived tumour vaccines. To prepare vaccine using murine tumour (ascites) cells, peritoneal fluid was collected from mice with late-stage BR5-Akt cancer. The intact peritoneal cavity was exposed and ascites, as well as two peritoneal wash samples with cold PBS, were collected using an $18 \mathrm{~g}$ needle and $5 \mathrm{ml}$ syringe inserted in the hypogastric region and positioned towards the caecum. In addition, ascites fluid was collected from patients with a diagnosis of ovarian cancer at the time of surgical debulking in accordance with approved IRB Protocol \#UNM INST 1509 entitled Single Institution (UNM) Prospective Laboratory Study of Cancer and Immune Cells in the Ascites Fluid of Ovarian Cancer Patients to Test Alternative Therapies. Human specimens were de-identified before transfer for research purposes. To isolate peritoneal cells, human or mouse ascites were centrifuged at 1,400 r.p.m. for $5 \mathrm{~min}$, after which the supernatant was removed, and RBCs were removed using ACK lysis buffer. Tumour cells were enriched using a $37 \mu \mathrm{m}$ reversible strainer. EpCAM ${ }^{+}$populations were evaluated by flow cytometry. Cells were then silicified and surface modified as previously described.

Adoptive transfer of $\mathrm{CD8}^{+} \mathrm{T}$ cells. Peritoneal washings were collected from tumour-bearing vaccinated (day 33 post tumour challenge) and control (tumour and vaccine naive) FVB mice as described above. Cells were enriched for $\mathrm{CD}^{+}$ $\mathrm{T}$ cells using the negative selection mouse CD8a $\mathrm{a}^{+} \mathrm{T}$-Cell Isolation MACS Cell Separation Kit (Miltenyi Biotec). Purification was confirmed post separation using flow cytometry. Cells were resuspended in cold PBS and adaptively transferred IP $\left(2 \times 10^{5}\right.$ cells per mouse $)$ to tumour and vaccine naive FVB mice. Control mice received sterile PBS IP. Twenty-four hours after transfer of $\mathrm{CD}^{+} \mathrm{T}$ cells, recipient mice were challenged with IP BR5-Akt-Luc2 ${ }^{+}$tumour cells $\left(2 \times 10^{5}\right.$ per mouse). Mice were then monitored for tumour progression using luminescence on IVIS Spectrum In Vivo Imaging System (Perkin Elmer).

Imaging tumour burden. For in vivo monitoring of tumour burden, mice with BR5-Akt-Luc2 tumours were administered $150 \mathrm{mg}$ luciferin per $\mathrm{kg}$ by IP injection, with a 10 min delay before imaging. Mice were then anaesthetized using $2.5 \%$ isoflurane, and 2D/3D bioluminescence images were acquired using the Xenogen IVIS Spectrum animal imager (Perkin Elmer). Region of interest measurements of total flux $\left(\mathrm{p} \mathrm{s}^{-1}\right)$ were acquired using Living Image Software (Perkin Elmer).

Murine tissue/cell collection. All mice were euthanized in accordance with the IACUC at the University of New Mexico. Spleens were mechanically dissociated, and RBC were eliminated using ACK or BD Pharm Lyse. Blood was collected by retro-orbital withdrawal using EDTA or heparin to prevent blood clotting. Omentum, peritoneal tumour, lungs, gut, brain and kidneys were dissected out and fixed in $10 \%$ buffered formalin. Tissues were embedded in paraffin, sectioned and stained with H\&E by the University of New Mexico Health Science Center Histology and Molecular Pathology Shared Resource. Bright-field images were acquired using a dissection microscope (World Precision Instruments) equipped with a Sony CCD progressive scan colour camera.

Biodistribution of vaccine. To track vaccine cells, BR5-Akt cancer cells were first incubated with Cy3-labelled MSN for $16 \mathrm{~h}$. Cells were then washed to remove free MSN and following silicification, $3 \times 10^{6}$ Si-PEI-CpG-MPL cells in $200 \mu \mathrm{l}$ PBS were IP administered to FVB mice $4 \mathrm{~d}$ post IP tumour challenge. Twenty-four hours later, mice were euthanized, and peritoneal tissues were frozen in optimal cutting temperature compound. Following sectioning, tissues were fixed in ice-cold acetone for $15 \mathrm{~min}$, labelled with anti-mouse CD11c FITC antibody and mounted in Prolong Gold mounting media containing DAPI. Images were acquired using a $63 \mathrm{X} / 1.4 \mathrm{NA}$ oil objective in sequential scanning mode using a Leica TCS SP8 confocal microscope. To study in vivo tissue biodistribution, CTFR-labelled vaccine cells were administered to FVB mice $4 \mathrm{~d}$ post tumour challenge. On days 5 and 6 , organs were isolated from mice ( $n=2$ to 3 per group) and the IVIS Spectrum was used to measure fluorescent intensities.

Immune cell phenotyping. Single-cell suspensions were first blocked with Fc receptor blockers ( $1 \mu \mathrm{g}$ anti-CD16/CD32 (clone 2.4G2)) and $1 \mu \mathrm{g}$ mouse IgG. Next, samples were surface stained with conjugated primary antibodies (1:250 dilution) at room temperature for $30 \mathrm{~min}$ in the dark. Samples were then stained with LIVE/ DEAD Fixable Aqua Dead Cell Stain for $15 \mathrm{~min}$ at room temperature in the dark. For intracellular cytokine analysis, cells were stimulated using eBioscience Cell Stimulation Cocktail (500X) plus Protein Transport Inhibitors Cocktail (500X) for $4 \mathrm{~h}$ in RMPI complete media. Cell permeabilization for intracellular staining was done using the eBioscience FoxP3/Transcription Factor Staining Buffer Set. Phenotyping was performed on stained cells using the Attune NxT flow cytometer and analysed using FlowJo 10.6 (Becton, Dickinson and Company).

Cytokine analysis. Neat peritoneal fluid from mice bearing BR5-Akt tumours at various stages of progression, with no treatment or following treatment with dehydrated vaccine, was collected and stored at $-80^{\circ} \mathrm{C}$. Samples were evaluated using a custom Milliplex MAP Mouse High Sensitivity T-Cell Panel using the Luminex MAGPIX System (Sigma Aldrich) without dilution as decribed by the vendor.

Blood metabolite measurements. Anti-coagulated blood metabolites and complete blood counts were measured on day 18 or 19 using the Vetscan VS2 Analyser and Comprehensive or Partial Diagnostic Profile discs (Abaxis) as described by the vendor.

Statistical Analysis. Measurements in this study were obtained from distinct samples. Graphpad Prism v6.0d was used to perform statistical analysis. KaplanMeier survival curves were analysed using log-rank Mantel-Cox, and Match SPSS and SAS tests were used for two and multiple group comparisons, respectively. For tumour burden comparisons, multiple $t$-tests assuming all rows were sampled from populations with the same scatter and correction for multiple comparisons using the Holm-Sidak method were used. Column statistics were analysed using unpaired two-tailed parametric $t$-tests with equal s.d. Graphs include means and error bars, with the latter representing s.d. or s.e.m. as indicated.

Reporting Summary. Further information on research design is available in the Nature Research Reporting Summary linked to this article.

\section{Data availability}

The main data supporting the results in this study are available within the paper and its Supplementary Information. The raw and analysed datasets generated during the study are too large to be publicly shared, but they are available for research purposes from the corresponding author on reasonable request. Source data for the figures are provided with this paper.

Received: 30 March 2020; Accepted: 16 August 2021; Published online: 1 November 2021

\section{References}

1. Sharma, P. \& Allison, J. P. Immune checkpoint targeting in cancer therapy: toward combination strategies with curative potential. Cell 161, 205-214 (2015)

2. Srivatsan, S. et al. Allogeneic tumour cell vaccines: the promise and limitations in clinical trials. Hum. Vaccin. Immunother. 10, 52-63 (2014).

3. Chiang, C. L., Coukos, G. \& Kandalaft, L. E. Whole tumour antigen vaccines: where are we? Vaccines 3, 344-372 (2015).

4. Sahin, U. \& Tureci, O. Personalized vaccines for cancer immunotherapy. Science 359, 1355-1360 (2018).

5. Kantoff, P. W. et al. Sipuleucel-T immunotherapy for castration-resistant prostate cancer. N. Engl. J. Med. 363, 411-422 (2010).

6. Hollingsworth, R. E. \& Jansen, K. Turning the corner on therapeutic cancer vaccines. NPJ Vaccines 4, 7 (2019).

7. Chiang, C. L. et al. A dendritic cell vaccine pulsed with autologous hypochlorous acid-oxidized ovarian cancer lysate primes effective broad antitumour immunity: from bench to bedside. Clin. Cancer Res. 19 , 4801-4815 (2013)

8. Kandalaft, L. E. et al. A Phase I vaccine trial using dendritic cells pulsed with autologous oxidized lysate for recurrent ovarian cancer. J. Transl. Med. 11, 149 (2013).

9. Kamigaki, T. et al. Immunotherapy of autologous tumour lysate-loaded dendritic cell vaccines by a closed-flow electroporation system for solid tumours. Anticancer Res. 33, 2971-2976 (2013).

10. Sarivalasis, A. et al. A phase I/II trial comparing autologous dendritic cell vaccine pulsed either with personalized peptides (PEP-DC) or with tumour lysate (OC-DC) in patients with advanced high-grade ovarian serous carcinoma. J. Transl. Med. 17, 391 (2019).

11. Pattillo, R. A., Komaki, R., Reynolds, M. \& Robles, J. Bacillus CalmetteGuerin immunotherapy in ovarian cancer. J. Reprod. Med. 33, 41-45 (1988).

12. Nishida, S. et al. Immune adjuvant therapy using Bacillus Calmette-Guerin cell wall skeleton (BCG-CWS) in advanced malignancies: a phase 1 study of safety and immunogenicity assessments. Medicine 98, e16771 (2019). 
13. Walker, J. J., Spear, J. R. \& Pace, N. R. Geobiology of a microbial endolithic community in the Yellowstone geothermal environment. Nature 434, 1011-1014 (2005).

14. Hamm, C. E. et al. Architecture and material properties of diatom shells provide effective mechanical protection. Nature 421, 841-843 (2003).

15. Kaehr, B. et al. Cellular complexity captured in durable silica biocomposites. Proc. Natl Acad. Sci. USA 109, 17336-17341 (2012).

16. Meraz, I. M. et al. Multivalent presentation of MPL by porous silicon microparticles favors $\mathrm{T}$ helper 1 polarization enhancing the anti-tumour efficacy of doxorubicin nanoliposomes. PLoS ONE 9, e94703 (2014).

17. Savage, D. J., Liu, X., Curley, S. A., Ferrari, M. \& Serda, R. E. Porous silicon advances in drug delivery and immunotherapy. Curr. Opin. Pharmacol. 13, 834-841 (2013).

18. Meraz, I. M. et al. Activation of the inflammasome and enhanced migration of microparticle-stimulated dendritic cells to the draining lymph node. Mol. Pharm. 9, 2049-2062 (2012).

19. Melisi, D. et al. Toll-like receptor 9 agonists for cancer therapy. Biomedicines 2, 211-228 (2014).

20. Lynn, G. M. et al. In vivo characterization of the physicochemical properties of polymer-linked TLR agonists that enhance vaccine immunogenicity. Nat. Biotechnol. 33, 1201-1210 (2015).

21. Blander, J. M. Phagocytosis and antigen presentation: a partnership initiated by Toll-like receptors. Ann. Rheum. Dis. 67 (Suppl. 3), iii44-iii49 (2008)

22. Kumar, S., Sunagar, R. \& Gosselin, E. Bacterial protein toll-like-receptor agonists: a novel perspective on vaccine adjuvants. Front Immunol. 10, 1144 (2019).

23. Ma, Y. F. \& Yang, Y. W. Delivery of DNA-based cancer vaccine with polyethylenimine. Eur. J. Pharm. Sci. 40, 75-83 (2010).

24. $\mathrm{Hu}, \mathrm{K}$. et al. An ocular mucosal administration of nanoparticles containing DNA vaccine pRSC-gD-IL-21 confers protection against mucosal challenge with herpes simplex virus type 1 in mice. Vaccine 29, 1455-1462 (2011).

25. Kuai, R. et al. Dual TLR agonist nanodiscs as a strong adjuvant system for vaccines and immunotherapy. J. Control. Release 282, 131-139 (2018).

26. de Nardo, D., de Nardo, C. M., Nguyen, T., Hamilton, J. A. \& Scholz, G. M. Signaling crosstalk during sequential TLR4 and TLR9 activation amplifies the inflammatory response of mouse macrophages. J. Immunol. 183, 8110-8118 (2009).

27. Moghimi, S. M. et al. A two-stage poly(ethylenimine)-mediated cytotoxicity: implications for gene transfer/therapy. Mol. Ther. 11, 990-995 (2005).

28. McConnell, K. I. et al. Reduced cationic nanoparticle cytotoxicity based on serum masking of surface potential. J. Biomed. Nanotechnol. 12, 154-164 (2016).

29. Doyle, S. E. et al. Toll-like receptors induce a phagocytic gene program through p38. J. Exp. Med. 199, 81-90 (2004)

30. Cole, G. A. Interferon- $\gamma$ ELISPOT assay for the quantitative measurement of antigen-specific murine CD8 ${ }^{+}$T-cells. Methods Mol. Biol. 302, 191-204 (2005).

31. Koster, B. D. et al. Autologous tumour cell vaccination combined with systemic CpG-B and IFN- $\alpha$ promotes immune activation and induces clinical responses in patients with metastatic renal cell carcinoma: a phase II trial. Cancer Immunol. Immunother. 68, 1025-1035 (2019).

32. Giuntoli, R. L. II et al. Ovarian cancer-associated ascites demonstrates altered immune environment: implications for antitumour immunity. Anticancer Res. 29, 2875-2884 (2009).

33. Lee, C. H., Wu, C. L., Tai, Y. S. \& Shiau, A. L. Systemic administration of attenuated Salmonella choleraesuis in combination with cisplatin for cancer therapy. Mol. Ther. 11, 707-716 (2005).

34. Burgdorf, S. \& Kurts, C. Endocytosis mechanisms and the cell biology of antigen presentation. Curr. Opin. Immunol. 20, 89-95 (2008).

35. Savina, A. et al. NOX2 controls phagosomal $\mathrm{pH}$ to regulate antigen processing during crosspresentation by dendritic cells. Cell 126, 205-218 (2006).

36. Lee, Y. K. et al. Kinetics and chemistry of hydrolysis of ultrathin, thermally grown layers of silicon oxide as biofluid barriers in flexible electronic systems. ACS Appl. Mater. Interfaces 9, 42633-42638 (2017).

37. Choi, E. \& Kim, S. Surface $\mathrm{pH}$ buffering to promote degradation of mesoporous silica nanoparticles under a physiological condition. J. Colloid Interface Sci. 533, 463-470 (2019).
38. Tanyi, J. L. et al. Personalized cancer vaccine effectively mobilizes antitumour T cell immunity in ovarian cancer. Sci. Transl. Med. https://doi.org/10.1126/ scitranslmed.aao5931 (2018).

39. Stump, C. T. et al. Remission-stage ovarian cancer cell vaccine with cowpea mosaic virus adjuvant prevents tumour growth. Cancers https://doi. org/10.3390/cancers13040627 (2021).

40. Prasad, S. et al. Polymer nanoparticles containing tumour lysates as antigen delivery vehicles for dendritic cell-based antitumour immunotherapy. Nanomedicine 7, 1-10 (2011).

41. Chiang, C. L. et al. Optimizing parameters for clinical-scale production of high IL-12 secreting dendritic cells pulsed with oxidized whole tumour cell lysate. J. Transl. Med. 9, 198 (2011).

42. Morehead, L. C. \& Cannon, M. J. Further clinical advancement of dendritic cell vaccination against ovarian cancer. Ann. Res. Hosp. https://doi. org/10.21037/arh.2018.08.02 (2018).

43. Nair-Gupta, P. et al. TLR signals induce phagosomal MHC-I delivery from the endosomal recycling compartment to allow cross-presentation. Cell 158, 506-521 (2014).

44. Xing, D. \& Orsulic, S. A mouse model for the molecular characterization of Brcal-associated ovarian carcinoma. Cancer Res. 66, 8949-8953 (2006).

45. Roby, K. F. et al. Development of a syngeneic mouse model for events related to ovarian cancer. Carcinogenesis 21, 585-591 (2000).

46. Higuchi, T. et al. CTLA-4 blockade synergizes therapeutically with PARP inhibition in BRCA1-deficient ovarian cancer. Cancer Immunol. Res. 3, 1257-1268 (2015).

47. Chiang, C. L., Ledermann, J. A., Rad, A. N., Katz, D. R. \& Chain, B. M. Hypochlorous acid enhances immunogenicity and uptake of allogeneic ovarian tumour cells by dendritic cells to cross-prime tumour-specific T cells. Cancer Immunol. Immunother. 55, 1384-1395 (2006).

48. Chiang, C. L. et al. Day-4 myeloid dendritic cells pulsed with whole tumour lysate are highly immunogenic and elicit potent anti-tumour responses. PLoS ONE 6, e28732 (2011)

\section{Acknowledgements}

We thank the University of New Mexico for the assistance and use of the Comprehensive Cancer Center Animal Models, Fluorescence Microscopy, Flow Cytometry and Histology Shared Resources, supported by NIH grant NCI P30 CA118100 (PI, Willman C.). This work was also supported by AIM center cores funded by NIH grant P20GM121176. We thank F. Schultz, I. Lagutina and M. Steinkamp for technical assistance.

\section{Author contributions}

R.E.S. and S.F.A. designed and co-directed the study. S.F., A.N. and L.T. conducted research. R.E.S., S.F.A., J.G., H.D.M. and D.F.K. contributed to the experimental design and conducted research. All authors reviewed the manuscript.

\section{Competing interests}

R.E.S., S.F.A., J.G. and C.J.B. are inventors on patent applications (US patent application no. 20200276286) based on technology presented in this manuscript.

\section{Additional information}

Extended data is available for this paper at https://doi.org/10.1038/s41551-021-00795-w.

Supplementary information The online version contains supplementary material available at https://doi.org/10.1038/s41551-021-00795-w.

Correspondence and requests for materials should be addressed to Rita E. Serda.

Peer review information Nature Biomedical Engineering thanks Sidi Bencherif, Lélia Delamarre and the other, anonymous, reviewer(s) for their contribution to the peer review of this work.

Reprints and permissions information is available at www.nature.com/reprints.

Publisher's note Springer Nature remains neutral with regard to jurisdictional claims in published maps and institutional affiliations.

(c) The Author(s), under exclusive licence to Springer Nature Limited 2021 
a

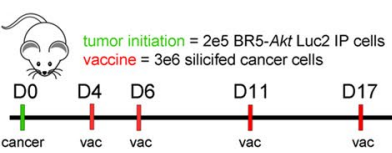

b

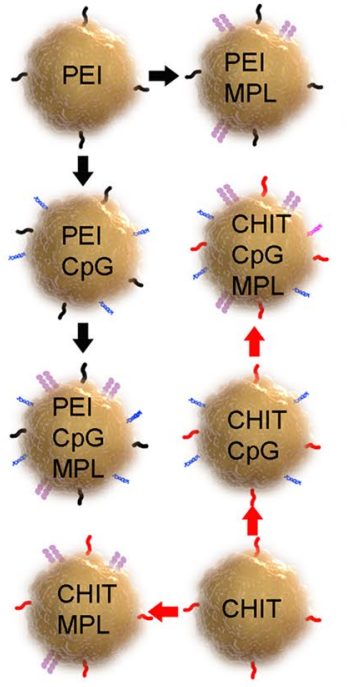

C
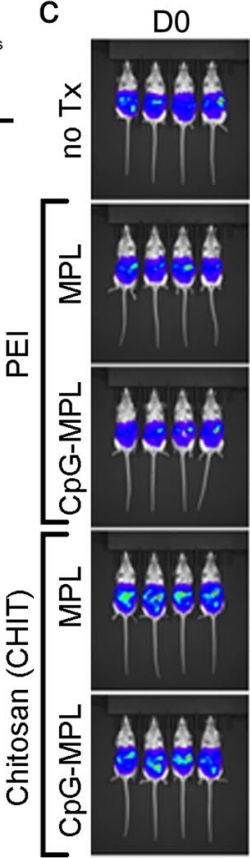
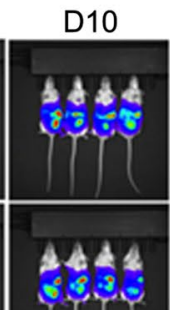
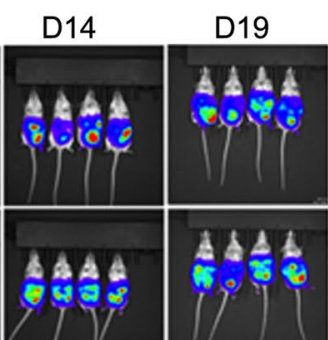
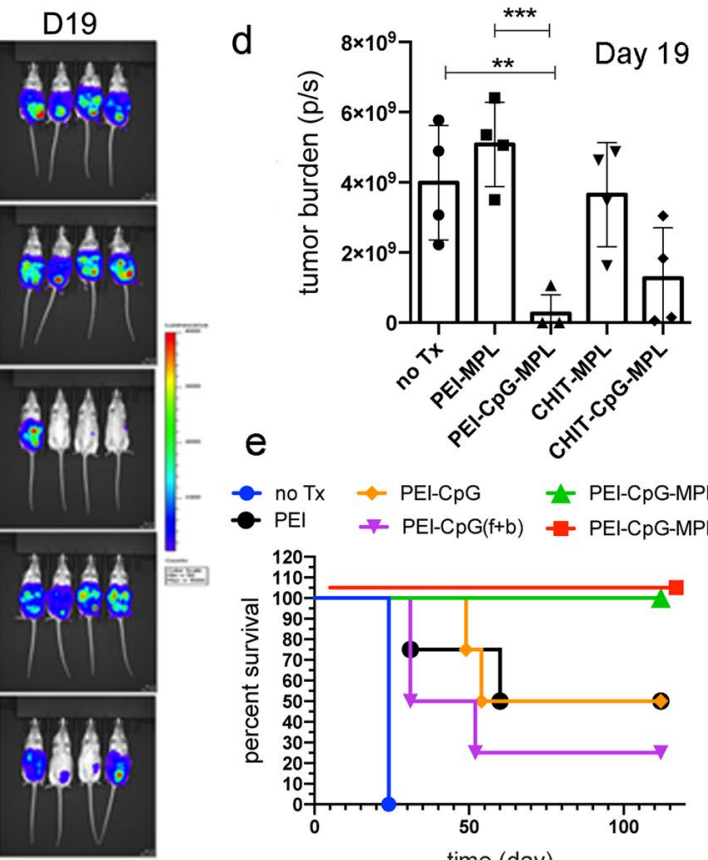

-

$\nrightarrow \mathrm{PEI}-\mathrm{CPG}$

\pm PEI-CpG-MPL

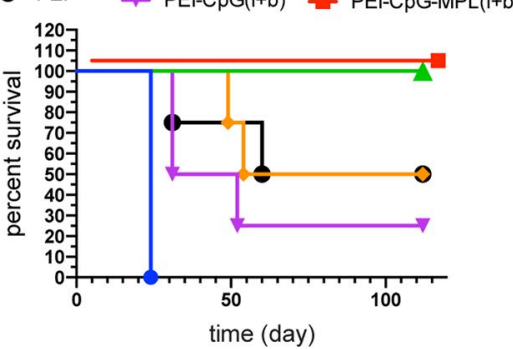

Extended Data Fig. 1 | Therapeutic efficacy of single vs dual TLR ligand vaccines. a) Timeline for BR5-Akt-Luc2 cancer cell and vaccine administration. b) Chitosan (CHIT) or polyethylimine (PEI) vaccine formulations containing MPL; CpG; or MPL plus CpG. c) IVIS bioluminescence images of FVB mice over time. d) Average tumour burden (photons/second; $\mathrm{p} / \mathrm{s}$ ) of each group shown in 'c' on Day 19 (Unpaired, two-tailed, parametric t-tests, s.d. error bars). e) Kaplan-Meier survival curves for mice treated with Si-PEl cells coated with CpG, or CpG and MPL. $f=$ free, and $b=$ bound TLR ligand; ( $n=4 / g$ roup, Log-rank Mantel-Cox: $p<0.0001$ with symbols to the right on the survival curve representing comparisons with no treatment (no Tx) controls and the symbol on the purple line comparing the $\mathrm{CpG}$ vs $\mathrm{CpG} / \mathrm{MPL}(\mathrm{f}+\mathrm{b})$ groups. ${ }^{\star} p<0.05,{ }^{\star \star} p<0.01, p<0.001$. 
a Vaccine internalization by DC
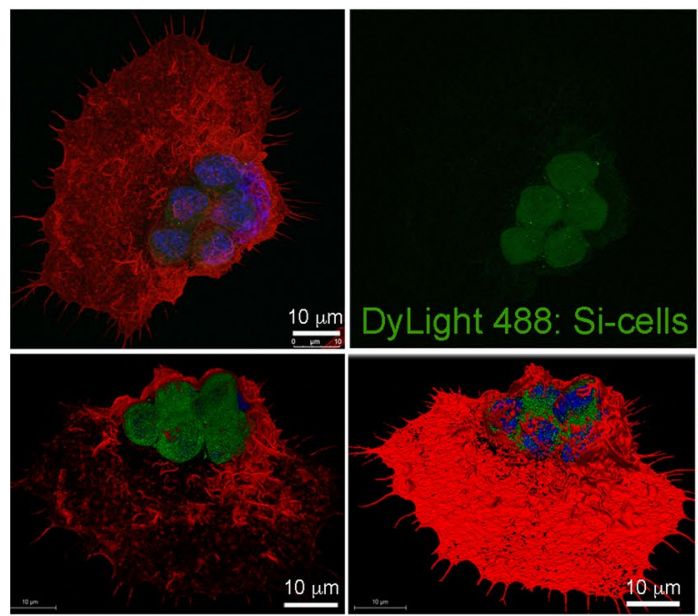

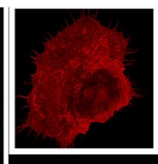

phalloidin: actin
C

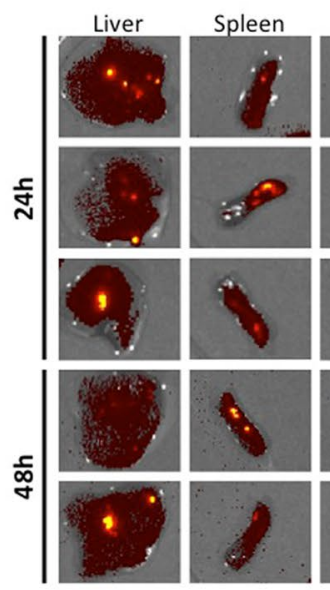

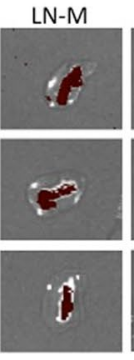

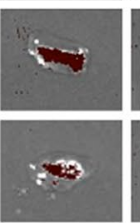

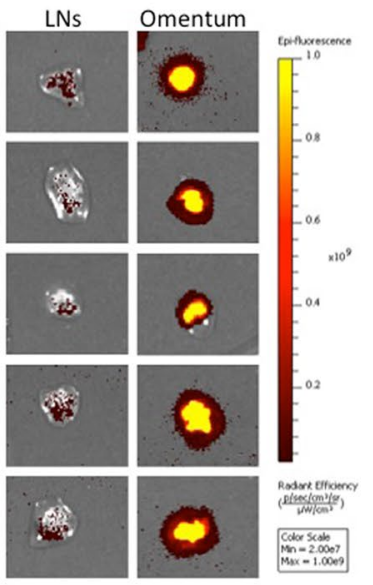

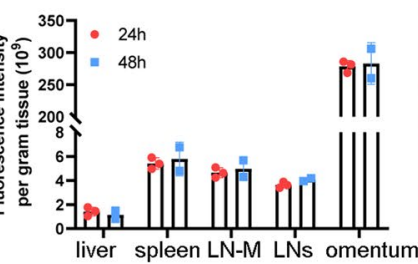

b DC activation/antigen presentation

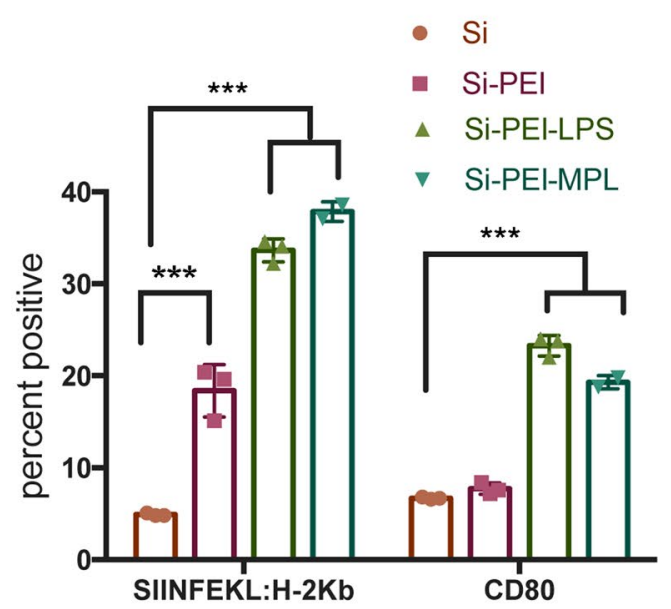

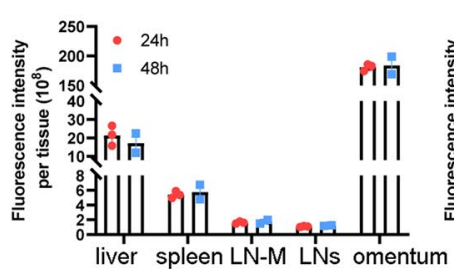

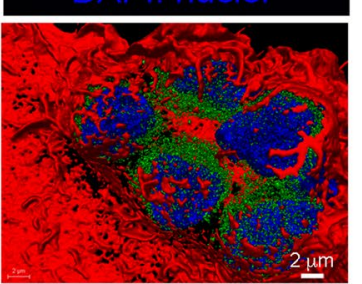

d vaccine:red, DC: green; nuclei: blue (DAPI)

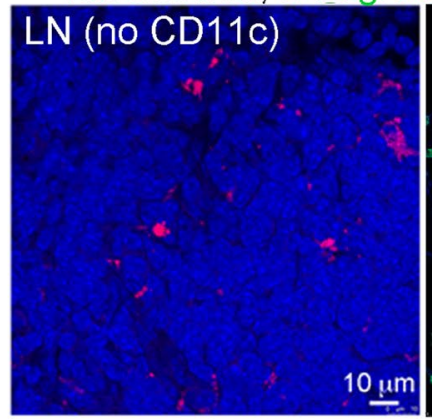

Omentum (24 hr) $\mathrm{x}$
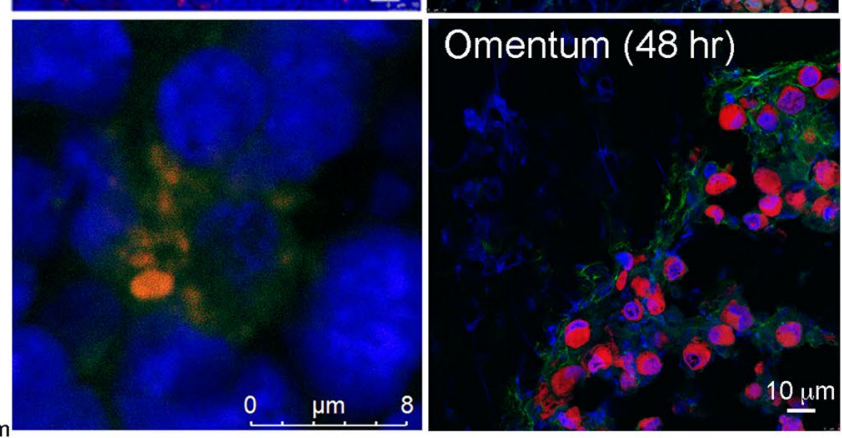

Extended Data Fig. 2 | Bone marrow-derived dendritic cell (BMDC) activation and internalization of silicified (Si) cells. a) 2D and 3D confocal images show five internalized Si-LPS-ID8ova cells (visualized via internalized DyLight 488-labelled nanoparticles) in a single BMDC. b) Flow cytometry analysis of SIINFEKL MHC-I ( $\mathrm{H}-2 \mathrm{~Kb}$ ) presentation and surface expression of CD80 in BMDC incubated with Si cells presenting null, PEI, or PEI plus LPS or MPL for 24 hours $\left(n=3 /\right.$ group; $\left.{ }^{\star \star \star} p<0.001\right)$. c) Cell Trace Far Red-labelled vaccine cells were predominately located in filtering and lymphatic organs (LN-M: mesenteric; LNs: Inguinal and axillary) 24 and $48 \mathrm{~h}$ post IP injection in tumour-bearing mice ( $n=2-3$ biological replicates). d) Fluorescent vaccine cells (red; Cy3) were located in peritoneal lymph nodes and the omentum, predominately in DC-rich areas, 24-48 hours post IP injection in naïve mice (green, right; CD11c FITC; blue nuclei, DAPI). Unpaired, two-tailed, parametric t-tests, SD error bars. 

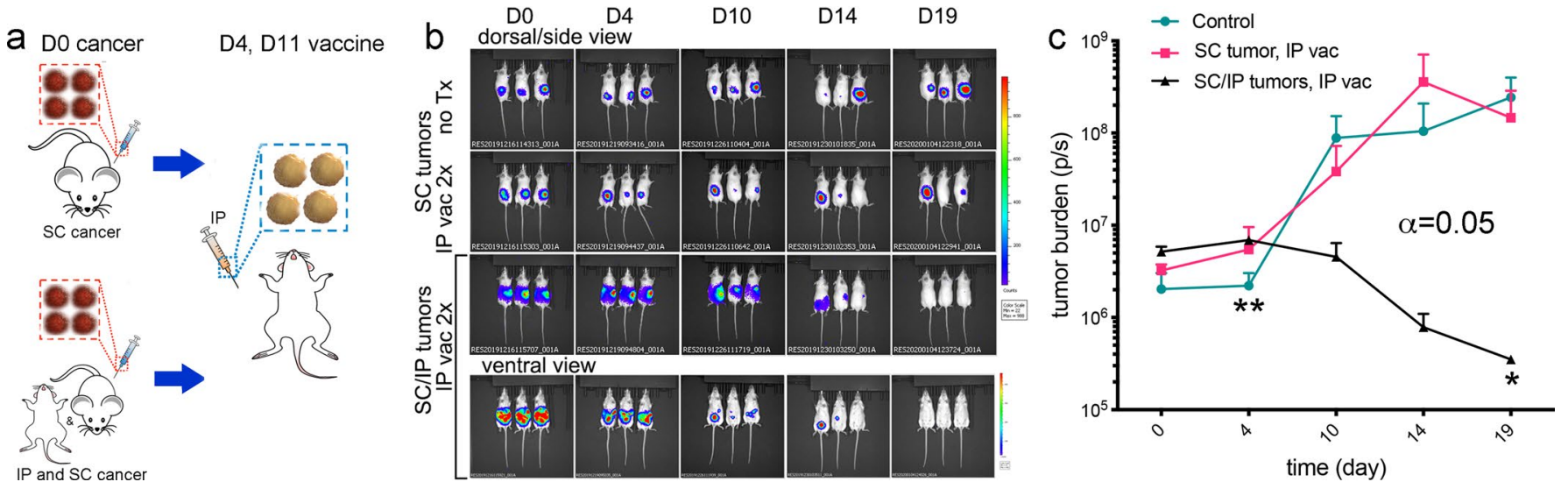

Extended Data Fig. 3 | Therapeutic vaccination in the tumour microenvironment enables systemic immunity. a) Experimental design and timeline $(n=3)$. b) IVIS bioluminescent images of BR5-Akt-Luc2 tumour growth. c) Graph of tumour burden (photons/sec) across time by treatment group (no treatment (no Tx) and tumour location. Intraperitoneal (IP) vaccination of mice bearing both subcutaneous (SC) and IP tumours cleared established tumours in both locations while mice with only SC tumours continued to display tumour growth ( $n=3 /$ group, Holm-Sidak multiple comparison; individual animal curves in $\mathrm{SI}) .{ }^{* \star} \mathrm{p}<0.01$. 

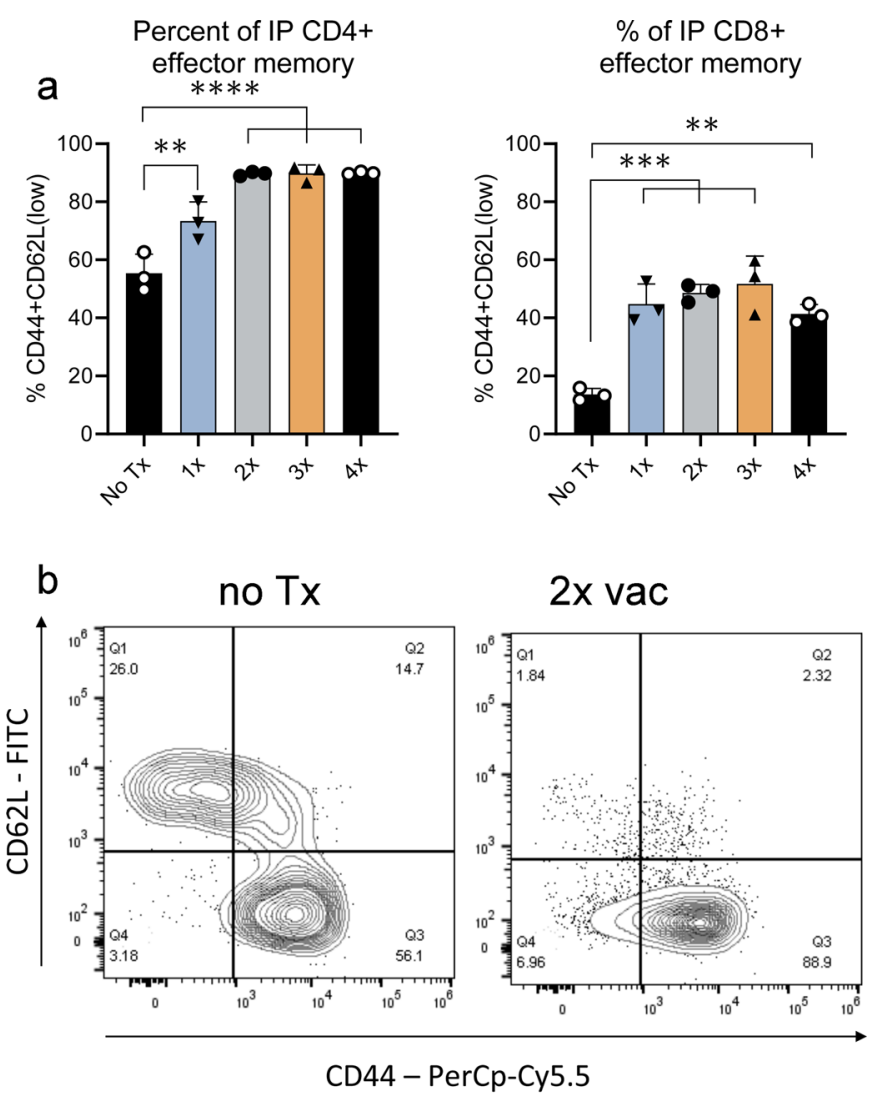

d FoxP3+/CD4+

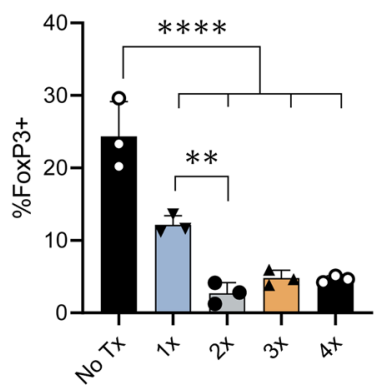

$\%$ of IP CD8+

effector memory

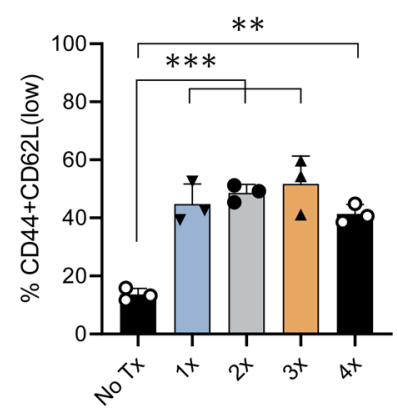

Spleenic CD4+ effector memory

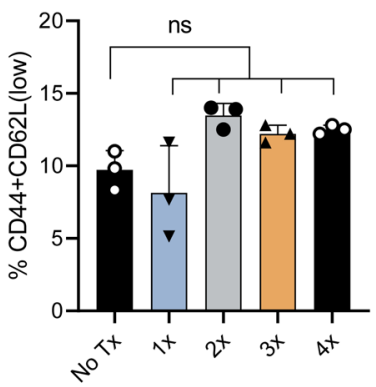

Spleen CD8+ effector memory

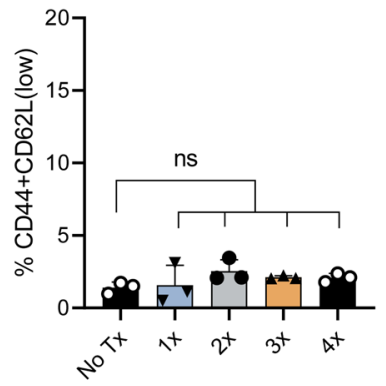

C

c no Tx 2x vac

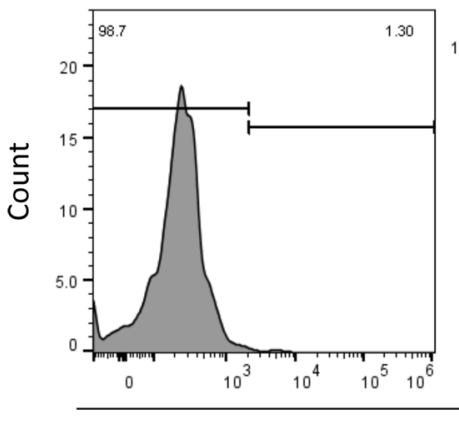

IFN $\gamma-\mathrm{AF} 488$

e

PD1+TIM3+/CD4+

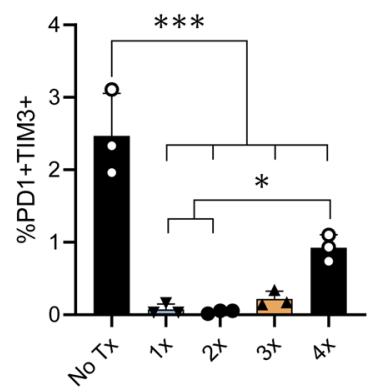

PD1+TIM3+/CD8+

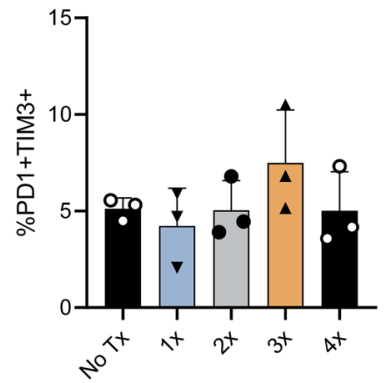

Extended Data Fig. 4 | Vaccination activates T cells in the tumour microenvironment. To test the effect of treatment number on IP immune responses, IP cells were collected and analysed for activation and functional status using flow cytometry on Day 19 following tumour challenge in mice vaccinated $1 \mathrm{x}, 2 \mathrm{x}, 3 \mathrm{x}, 4 \mathrm{x}$ or those receiving no treatment (PBS; no Tx) on days 4, 6,11 and 17. a) Proportion of IP CD4 and CD8 cells with effector memory phenotypes $\left(C D 44^{+}\right.$CD62 ${ }^{\text {low }}$ ). b) Representative dot plot for effector memory CD4+ IP cells (CD44 vs CD62L. c) Representative plot for IFN $\gamma$ expression by IP CD4 ${ }^{+}$ cells from with no vaccination vs $2 x$ vaccination. d) Proportion of IP CD4+ cells expressing the regulatory markers CTLA4 and FoxP3. e) Proportion of $\mathrm{CD}^{+}$and $\mathrm{CD} 8^{+}$IP cells expressing PD1 and Tim3. $\mathrm{n}=3$ biological replicates; unpaired, two-tailed, parametric $\mathrm{t}$-tests, $\mathrm{SD}$ error bars, ${ }^{\star} \mathrm{p}<0.05,{ }^{\star \star} \mathrm{p}<0.01$, ${ }^{\star \star \star} p<0.001$. 


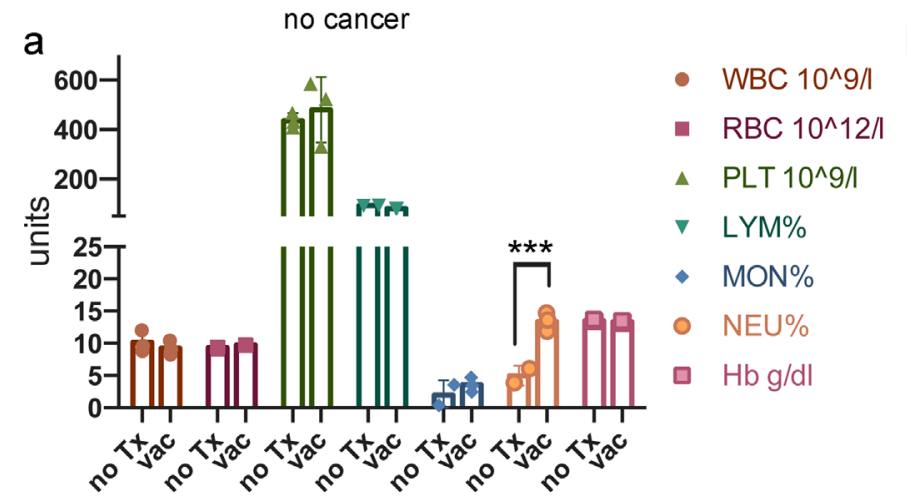

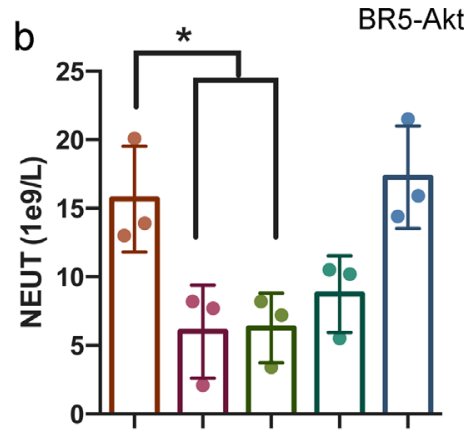

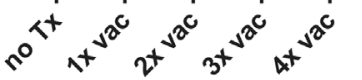

d

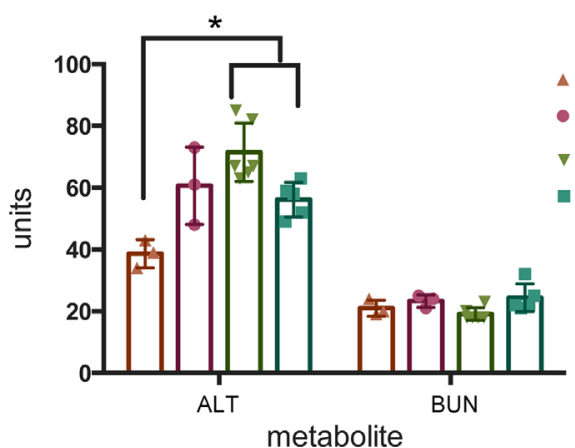

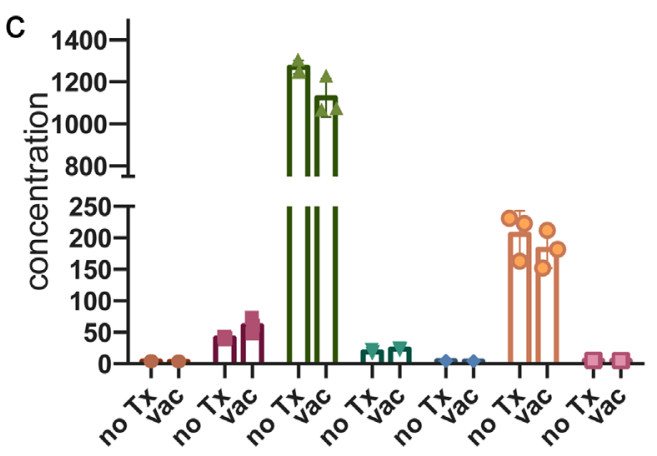

- ALB

- ALT

$\triangle$ AMY

$\checkmark$ BUN

- Phos

- Glu

$\square$ TP

Extended Data Fig. 5 | CBC and blood metabolite analysis supports vaccine safety. Tumour naïve $(\mathbf{a}, \mathbf{c})$ or cancer challenged $(\mathbf{b}, \mathbf{d}) \mathrm{FVB}$ mice $(n=3$ biological replicates; unpaired, two-tailed, parametric t-tests) were vaccinated 1-4x. Graphs show cell counts by population and blood metabolites obtained using the Abaxis VetScan System and piccolo metabolite discs. ${ }^{\star} p<0.05,{ }^{\star \star \star} p<0.001$. 


\section{Reporting Summary}

Nature Portfolio wishes to improve the reproducibility of the work that we publish. This form provides structure for consistency and transparency in reporting. For further information on Nature Portfolio policies, see our Editorial Policies and the Editorial Policy Checklist.

\section{Statistics}

For all statistical analyses, confirm that the following items are present in the figure legend, table legend, main text, or Methods section.

n/a Confirmed

$\bigotimes$ The exact sample size $(n)$ for each experimental group/condition, given as a discrete number and unit of measurement

$\searrow$ A statement on whether measurements were taken from distinct samples or whether the same sample was measured repeatedly

$\triangle$ The statistical test(s) used AND whether they are one- or two-sided

Only common tests should be described solely by name; describe more complex techniques in the Methods section.

$\bigotimes$ A description of all covariates tested

\ A description of any assumptions or corrections, such as tests of normality and adjustment for multiple comparisons

$\triangle$ A full description of the statistical parameters including central tendency (e.g. means) or other basic estimates (e.g. regression coefficient)

AND variation (e.g. standard deviation) or associated estimates of uncertainty (e.g. confidence intervals)

$\varnothing$ For null hypothesis testing, the test statistic (e.g. $F, t, r$ ) with confidence intervals, effect sizes, degrees of freedom and $P$ value noted

Give $P$ values as exact values whenever suitable.

Х $\square$ For Bayesian analysis, information on the choice of priors and Markov chain Monte Carlo settings

Х $\square$ For hierarchical and complex designs, identification of the appropriate level for tests and full reporting of outcomes

$\square$ Estimates of effect sizes (e.g. Cohen's $d$, Pearson's $r$ ), indicating how they were calculated

Our web collection on statistics for biologists contains articles on many of the points above.

\section{Software and code}

Policy information about availability of computer code

Data collection PerkinElmer Avio 500 Inductively Coupled Plasma - Optical Emission Spectroscopy (ICP-OES) with software Syngistix version 4.5 for measuring Si in biological samples; Malvern Zeta Sizer, version 7.11 for measuring surface charge; BioTek Synergy H1, Gen5 version 2.01.13 plate reader for measuring fluorescence/colorimetry/absorbance; Clariostar BMG LABTECH with MARS Data Analysis versions 5.0 for measuring fluorescence/absorbance/luminesence.

Data analysis FlowJo version 10.6 for flow-cytomery analysis.

For manuscripts utilizing custom algorithms or software that are central to the research but not yet described in published literature, software must be made available to editors and reviewers. We strongly encourage code deposition in a community repository (e.g. GitHub). See the Nature Portfolio guidelines for submitting code \& software for further information.

\section{Data}

Policy information about availability of data

All manuscripts must include a data availability statement. This statement should provide the following information, where applicable:

- Accession codes, unique identifiers, or web links for publicly available datasets

- A description of any restrictions on data availability

- For clinical datasets or third party data, please ensure that the statement adheres to our policy

The main data supporting the results in this study are available within the paper and its Supplementary Information. Source data for the figures are provided with this paper. The raw and analysed datasets generated during the study are too large to be publicly shared, yet they are available for research purposes from the corresponding authors on reasonable request. 


\section{Field-specific reporting}

Please select the one below that is the best fit for your research. If you are not sure, read the appropriate sections before making your selection.

$\bigotimes$ Life sciences

Behavioural \& social sciences

Ecological, evolutionary \& environmental sciences

For a reference copy of the document with all sections, see nature.com/documents/nr-reporting-summary-flat.pdf

\section{Life sciences study design}

All studies must disclose on these points even when the disclosure is negative.

Sample size

Pilot project data on vaccine-efficacy studies using syngeneic mouse models of ovarian cancer showed that 8 vaccinated mice were able to fully eliminate cancer cells ( $100 \%$ response rate) while untreated mice $(n=8)$ all died at approximately 25 days after cancer challenge. Using the IVIS Spectrum bioluminescence (photons/second) data from each group, the difference in means is $99.995 \%$. Using a type-I error rate ( $\alpha$ ) of 0.05 or 0.01 , a $95 \%$ probability power analysis predicts that we can show that therapeutic outcomes from treated (vaccinated) and untreated mouse groups are distinct with a sample size of 3 or 4 , respectively. For statistical comparisons, Log-rank (Mantel-Cox) and GehanBreslow-Wilcoxon tests were used for two-curve comparisons presented in the Kaplan-Meier survival curves. Unpaired, parametric, two-tail $t$ tests assumed populations had the same standard deviation.

Data exclusions No data were excluded.

Replication All studies were replicated.

Randomization Upon arrival, mice were randomized into cages by groups, with no treatments or imaging done prior to randomization.

Blinding The researchers were blinded to group allocation (which was performed by personnel from the UNM animal-resource facility) during data collection and analysis.

\section{Reporting for specific materials, systems and methods}

We require information from authors about some types of materials, experimental systems and methods used in many studies. Here, indicate whether each material, system or method listed is relevant to your study. If you are not sure if a list item applies to your research, read the appropriate section before selecting a response.

Materials \& experimental systems

n/a Involved in the study

Methods

$\square \bigotimes$ Antibodies

\ $\square$ Eukaryotic cell lines

Х $\square$ Palaeontology and archaeology

\begin{tabular}{l|l}
\hline n/a & Involved in the study \\
$\square$ & $\square$ ChIP-seq \\
$\square$ & $\square$ Flow cytometry \\
$\square$ & $\square$ MRI-based neuroimaging
\end{tabular}

$\square$ \ Animals and other organisms

$\square$ \uman research participants

$\bigotimes \square$ Clinical data

\ $\square$ Dual use research of concern

\section{Antibodies}

Antibodies used

CD11c FITC (HL3), CD11c FITC (B-ly6), CD326 (EpCAM, G8.8) APC, CD326 (MaH EpCAM IB7) eFluor 660, CD3 (17A2) APC-eFluor 780, CD4 (GK1.5) APC, CD8a (53-6.7) efluor 450 and Alexa Flour 488, CD11b (M1/70) APC and FITC, CD11c (N418) PerCP-Cyanine5.5 and PECy7, CD40 (3/23) PE, CD44 (IM7) PerCP-Cyanine5.5, CD62L (L-selectin, MEL 14) FITC, CD152 (CTLA-4, UC10-4B9) PE and PerCpCy5.5, CD279 (PD-1, J43) PE-Cyanine7, FOXP3 (FJK-16s) PE, IFN gamma (XMG1.2) Alexa Fluor 488, MHC Class II (I A/I E) (M5/114.15.2) FITC, GATA-3 PerCP-eFlour 710 (TWAJ), TNFa PerCP-eFlour 710 (MP6-XT22), CD45R (B220) FITC, Fc receptor blockers (anti-CD16/ CD32 (clone 2.4G2)), mouse IgG (31205) were purchased from eBioscience/Thermo Fisher Scientific. IL-4 - APC (11B11), CD152 (CTLA-4) PerCP, TIM3 (B8.2C12) APC and CD11C FITC (N418; Amnis BMDC and mouse tissues) were purchased from BioLegend. IL-2 PE (JES6-5H4) was purchased from BD Bioscience.

Single-cell suspensions were first blocked with Fc receptor blockers ( $1 \mu \mathrm{g}$ anti-CD16/CD32 (clone 2.4G2) and $1 \mu \mathrm{g}$ mouse IgG. Next, samples were surface stained with conjugated primary antibodies (1:250 dilution) at room temperature for 30 minutes in the dark. Samples were then stained with LIVE/DEAD Fixable Aqua Dead Cell Stain for $15 \mathrm{~min}$ at room temperature in the dark. For intracellular cytokine analysis, cells were stimulated using eBioscience Cell Stimulation Cocktail (500X) plus Protein Transport Inhibitors Cocktail (500X) for 4 hours in RMPI complete media. Cell permeabilization for intracellular staining was done using the eBioscience FoxP3 / Transcription Factor Staining Buffer Set. 


\section{Animals and other organisms}

Policy information about studies involving animals; ARRIVE guidelines recommended for reporting animal research

Laboratory animals Female FVB and C57BL/6 mice aged 6-8 weeks at study initiation were used.

Wild animals The study did not involve wild animals.

Field-collected samples The study did not involve samples collected from the field.

Ethics oversight

All animal protocols were approved by the Institutional Animal Care and Use Committee at the University of New Mexico.

Note that full information on the approval of the study protocol must also be provided in the manuscript.

\section{Human research participants}

Policy information about studies involving human research participants

Population characteristics

Ascites fluid was obtained from patients with a diagnosis of ovarian cancer at the time of surgical debulking or paracentesis.

Recruitment

All female participants, eighteen years old or older, regardless of ethnicity, who were undergoing cytoreductive surgery for ovarian cancer were eligible for the study. The participants had to have ability to understand, and the willingness to sign, a written informed-consent document.

Ethics oversight

IRB Protocol \#UNM INST 1509, entitled "Single Institution (UNM) Prospective Laboratory Study of Cancer and Immune Cells in the Ascites Fluid of Ovarian Cancer Patients to Test Alternative Therapies".

Note that full information on the approval of the study protocol must also be provided in the manuscript.

\section{Flow Cytometry}

Plots

Confirm that:

Х The axis labels state the marker and fluorochrome used (e.g. CD4-FITC).

Х The axis scales are clearly visible. Include numbers along axes only for bottom left plot of group (a 'group' is an analysis of identical markers).

All plots are contour plots with outliers or pseudocolor plots.

Х A numerical value for number of cells or percentage (with statistics) is provided.

\section{Methodology}

Sample preparation

Instrument

Software

Cell population abundance

Gating strategy
All mice were euthanized, in accordance with the protocol approved by the Institutional Animal Care and Use Committee at the University of New Mexico. Spleens were mechanically dissociated. Blood was collected retro-orbitally with EDTA or heparin. Peritoneal cells were collected by washing the IP cavity of euthanized mice with cold, sterile PBS.

All samples were kept on ice during processing, with the exception of the antibody-staining steps. RBCs were eliminated using ACK or BD Pharm Lyse buffer. Single-cell suspensions were first blocked with Fc receptor blockers ( $1 \mu \mathrm{g}$ anti-CD16/CD32 (clone 2.4G2) and $1 \mu \mathrm{g}$ mouse IgG. Next, samples were surface stained with conjugated primary antibodies at room temperature for 30 minutes in the dark. Samples were then stained with LIVE/DEAD Fixable Aqua Dead Cell Stain for 15 min at room temperature in the dark.

For intracellular cytokine analysis, cells were stimulated using eBioscience Cell Stimulation Cocktail (plus protein transport inhibitors) 500x for 4 hours in RMPI complete media. Cell permeabilization for intracellular staining was done using the eBioscience FoxP3 / Transcription Factor Staining Buffer Set.

Attune NxT or Calibur Flow Cytometer.

FACSDiva, Cellquest, and FlowJo (10.6) (Becton, Dickinson and Company).

No post-sort fractions were collected.

Samples were first gated based on side scatter area vs. height for single-cell populations. Next, cells were sorted for live vs. dead using LIVE/DEAD Fixable Aqua Dead Cell Stain Kit (eBioscience/Thermo Fisher Scientific) vs. side scatter. Live cells were sorted using side scatter vs. CD3 to identify lymphocytes. CD3+ lymphocytes were then sub-gated based on CD4 vs. CD8.

For effector/naïve/central memory panel, CD4 and CD8 were gated on CD44 vs CD62L. For exhausted phenotypes, CD4 and CD8 were sub-gated based on PD-1 and TIM3 and LAG3. For cytokine expression CD4 and CD8 cells were gated on IFNg vs 
TNFa. For the gating of cytokine production we used unstimulated matched controls. Regulatory and actively dividing cells were defined by sub-gating $\mathrm{CD} 4$ and $\mathrm{CD} 8$ on by $\mathrm{CD} 4$ or $\mathrm{CD} 8$ vs. FoxP3, and gating was based on FMO controls. For co-staining studies to identify association of BMDCs with coated vaccine cells, we stained vaccine cells and BMDCs with either cell trace violet, cell trace far-red or CFSE (different combinations were used in separate repeats of this experiment). Co-cultured cell populations were then used (immediately after taking out of culture and storing on ice) for flow cytometry, and percent uptake was calculated based on the ratio of cells staining positive for vaccine and BMDCs vs. the total positive for the vaccine. positive for vaccine and BMDCs vs. the total positive for the vaccine.

Х Tick this box to confirm that a figure exemplifying the gating strategy is provided in the Supplementary Information. 